\title{
RETALIAÇÃO CRUZADA EM PROPRIEDADE INTELECTUAL: alternativa para uma atuação mais eficaz dos países em desenvolvimento no sistema de solução de controvérsias da OMC
}

\author{
CROSS-RETALIATION IN INTELLECTUAL PROPERTY: TOWARDS A MORE EFFECTIVE
}

PERFORMANCE OF DEVELOPING COUNTRY IN THE WTO DISPUTE SETTLEMENT SYSTEM

\author{
Daniel do Amaral Arbix* \\ Abrão Árabe Neto**
}

\begin{abstract}
Resumo:
O presente artigo trata da retaliação cruzada, com enfoque na área de propriedade intelectual, como alternativa aos recursos mais usuais previstos pelas regras de solução de controvérsias da Organização Mundial do Comércio (OMC). O instituto é examinado da perspectiva dos países em desenvolvimento e sugerido como capaz de tornar sua atuação no Órgão de Solução de Controvérsias mais eficaz. O funcionamento do sistema de solução de controvérsias da OMC e as possibilidades de retaliação são inicialmente descritos para que se proceda à análise dos requisitos para a autorização de retaliações cruzadas e da experiência prática acumulada nas disputas da OMC. Em seguida, são expostas as particularidades das retaliações cruzadas em direitos de propriedade intelectual e se busca identificar os reflexos positivos e negativos de sua utilização, propostas para seu aprimoramento, bem como os projetos legislativos para sua regulamentação interna no Brasil. Conclui-se com um balanço do recurso às retaliações cruzadas em propriedade intelectual pelos países em desenvolvimento, à luz da controvérsia US - Upland Cotton envolvendo Brasil e EUA.

Palavras-chave: Organização Mundial do Comércio. Solução de controvérsias. Retaliação cruzada. Propriedade intelectual. Países em desenvolvimento. Comércio internacional.
\end{abstract}

\begin{abstract}
:
This article analyses cross-retaliation, especially that which targets intellectual property rights as an alternative to the more usual instruments available in the World Trade Organization's (WTO) dispute settlement provisions. Cross-retaliation is examined from the perspective of developing countries, and recommended due to its potential to enhance their participation in the Dispute Settlement Body. First, the procedures of the WTO's dispute settlement system and the possibilities to retaliate are described in order to allow the study of the requirements for cross-retaliations to be authorized and of the practical experience accumulated during the WTO disputes. Then, the peculiarities of cross-retaliation in intellectual property are exposed with the objective of identifying the positive and negative reflexes of its use, proposals for its improvement, and the parliamentary bills which aim to provide
\end{abstract}

\footnotetext{
Mestrando em Direito Internacional na Faculdade de Direito da Universidade de São Paulo. Consultor do Programa das Nações Unidas para o Desenvolvimento (PNUD) junto à Secretaria de Assuntos Legislativos do Ministério da Justiça; e-mail: d.arbix@uol.com.br.

** Mestrando em Direito das Relações Econômicas Internacionais na Pontifícia Universidade Católica de São Paulo. Bolsista do Conselho Nacional de Desenvolvimento Científico e Tecnológico (CNPq) e participante da Turma n. 16 do Programa de Treinamento para Jovens Advogados na Missão do Brasil em Genebra (jan./abr. 2008); e-mail: abraoarabe@hotmail.com.
} 
for cross-retaliation in Brazil. The article concludes with a summary of the requests by developing countries to cross-retaliate on intellectual property rights, in light of the 'US - Upland Cotton' dispute between Brazil and the US.

Keywords: World Trade Organization. Dispute settlement. Cross-retaliation. Intellectual property. Developing countries. International trade.

\section{Introdução}

Uma das críticas mais contundentes que se faz ao sistema de solução de controvérsias da Organização Mundial do Comércio (“OMC") diz respeito à eficácia dos mecanismos de implementação de suas decisões. Quando um Membro, considerado vencido em um conflito analisado no âmbito da entidade, não cumpre voluntariamente o conteúdo de uma determinação que lhe foi dirigida pelo Órgão de Solução de Controvérsias ("OSC"), vislumbra-se a necessidade de instrumentos eficazes para induzir tal cumprimento. Contudo, em hipóteses de recalcitrância, os recursos previstos pelas regras da OMC, na forma como utilizados atualmente, muitas vezes se mostram insuficientes para permitir a pacificação satisfatória do litígio, notadamente quando o confronto opõe países em desenvolvimento ("PEDs") a países desenvolvidos ("PDs").

Diante desse cenário, o presente artigo tenciona analisar o instituto da retaliação cruzada, especialmente em propriedade intelectual ("PI"), como alternativa para aumentar a eficácia da atuação dos PEDs no sistema de solução de controvérsias da OMC. Após uma concisa introdução sobre o funcionamento desse sistema (Capítulo 2), e de uma explanação geral sobre retaliações (Capítulo 3), o estudo apresenta um roadmap das etapas necessárias para se obter autorização para retaliar de forma cruzada, examinando as normas pertinentes e a experiência acumulada em sua interpretação pela OMC (Capítulo 4). Em seguida, concentra-se o exame nas feições específicas das retaliações cruzadas em direitos de PI, identificando-se reflexos positivos e negativos de sua utilização, propostas para seu aprimoramento e, em atenção aos interesses brasileiros, os projetos de lei que pretendem regulamentar seu uso no território nacional (Capítulo 5). Por fim, concluise com um balanço geral do recurso às retaliações em PI pelos PEDs como opção para incrementar seus resultados nos contenciosos da OMC.

Considerando a recente vitória do Brasil no painel de implementação da controvérsia do Algodão (US - Upland Cotton), na qual se reconheceu a situação de descumprimento da decisão pelos EUA (OMC, 2008), e que abre caminho para futura aplicação de retaliações, bem como as reiteradas manifestações do Governo brasileiro sobre a possibilidade de recorrer a sanções em PI, resta evidente a importância do tema, que se coloca como uma das prioridades da agenda diplomática brasileira atual. 


\section{Breves comentários sobre o sistema de solução de controvérsias da OMC}

O sistema de solução de controvérsias da OMC é composto por um conjunto de etapas que, em última análise, visam à pacificação dos conflitos surgidos entre seus Membros. Seu diploma basilar é o Entendimento Relativo às Normas e Procedimentos sobre Solução de Controvérsias ("ESC"), ${ }^{1}$ que contém as regras pertinentes para o adequado funcionamento do mecanismo.

A etapa inicial desse procedimento consiste na fase de consultas, representativa da vertente diplomática do sistema. Buscando estimular soluções acordadas pelas próprias partes em conflito, o ESC determina, com acerto, a obrigatoriedade de um estágio preliminar de negociações, desenhado para aproximar os contendores e permitir a discussão de uma solução que lhes seja mutuamente satisfatória. ${ }^{2}$ Frustrada a tentativa de autocomposição, disponibiliza-se ao reclamante o acesso a uma via de caráter predominantemente jurisdicional, na qual a apreciação da controvérsia é remetida a um grupo de especialistas (painel). ${ }^{3 / 4}$ Estabelecido especificamente para o caso em concreto, o painel investe-se na missão de propor uma solução objetiva ao litígio, fundada nas normas do sistema multilateral de comércio. Essa recomendação não necessariamente é final, podendo ser contestada em grau de recurso, cujo exame fica a cargo do Órgão Permanente de Apelação (“OA"). ${ }^{5}$ A matéria apelável, todavia, restringe-se às questões de direito e interpretações jurídicas levadas a efeito pelo painel. Na prática, o OA manifesta sua decisão em 90 dias, na forma de um relatório.

Para revestir-se de validade, o relatório final deverá ser ratificado pelo OSC, que é integrado por todos os Membros da OMC. A exigência, contudo, é facilmente preenchida, uma vez que o relatório somente poderá ser recusado na improvável hipótese de reprovação unânime dos Membros, neles incluída a própria parte vencedora (consenso

\footnotetext{
Anexo II do Acordo Constitutivo da OMC.

2 Considerando um universo de 365 controvérsias iniciadas na OMC até abril de 2008, 168 disputas (46\%) foram encerradas ainda na fase de consultas, sem avançar para a etapa posterior de estabelecimento de painel.

3 O presente artigo utilizará, em consonância com a tradição consolidada na doutrina brasileira especializada, o vocábulo "painel" para fazer menção ao grupo de especialistas formado para apreciar juridicamente, e em caráter original, uma controvérsia na OMC. Sem embargo, vale advertir que a tradução do ESC para o português adotada pelo Ministério das Relações Exteriores emprega a expressão "grupo especial", em sintonia com a versão oficial do documento em línguas francesa ("groupe spécial") e espanhola ("grupo especial"). Disponível em: $<$ http://www.mre.gov.br/portugues/ministerio/sitios_secretaria/cgc/controversias.doc $>$. Acesso em: 09 mar. 2008. Cretella Neto (2002:74-75) assinala que o uso do termo "painel" consiste em anglicismo, visto que seu significado no vernáculo não compreende o de grupo de especialistas composto para apreciar uma questão jurídica.

4 Até o presente momento foram estabelecidos 197 painéis, o que corresponde a $54 \%$ do total de controvérsias verificadas na OMC. De todos eles, $144(73 \%)$ redundaram na emissão de um relatório apresentado para as partes.

5 O percentual atual de apelações é de aproximadamente $70 \%$ (houve 99 recursos de um total de 144 relatórios de painéis distribuídos para as partes).
} 
negativo). Adotado o relatório, parte-se para a sensível etapa de implementação da decisão, na qual se busca a modificação da conduta considerada inconsistente com as normas da OMC. Nesse caso, em um primeiro instante, assegura-se ao reclamado a oportunidade de efetivar espontaneamente as recomendações da entidade em um prazo razoável (geralmente fixado por arbitragem). ${ }^{6}$ Esgotado esse prazo, é necessário verificar se a parte vencida observou integralmente a decisão, corrigindo os desvios apontados pelo relatório adotado pelo OSC. Havendo concordância em relação ao status de adimplemento, a divergência encontra seu termo. Todavia, é possível que o reclamado alegue o cumprimento da determinação, sendo o fato contestado pela parte adversa. Verificado tal impasse, levantase a questão do cumprimento: o Membro vencido realmente implementou as alterações necessárias para a total efetivação da decisão? Referidas alterações são integralmente consistentes com as normas da OMC?

Diante dessas indagações, um painel de implementação (compliance panel), composto, preferencialmente, pelos especialistas que abordaram a controvérsia principal, pode ser constituído para elucidar a nova pendência,,$^{7 / 8}$ cabendo recurso de sua decisão ao OA. ${ }^{9}$ Caso comprovado o descumprimento do relatório, ao reclamante abre-se a prerrogativa de negociar compensações ou retaliar o Membro sucumbente. Como as compensações representam um benefício tarifário (de cunho não-pecuniário), que deve ser estendido a todos os Membros, elas raramente se concretizam na prática. Assim, a recalcitrância, via de regra, leva o Membro vencedor a solicitar autorização para aplicar sanções. ${ }^{10}$

\section{Retaliações na $\mathrm{OMC}$}

\subsection{Noções gerais}

Os termos "retaliação" e "sanção" não estão positivados em nenhum trecho dos acordos da OMC. Em verdade, a idéia neles encerrada é abordada de forma um pouco mais técnica: o ESC, ao fazer referência a tais institutos, lança mão da expressão "suspensão de concessões ou de outras obrigações decorrentes dos acordos abrangidos". ${ }^{11}$

\footnotetext{
6 O prazo razoável para implementação de recomendações e determinações adotadas pelo OSC foi definido com recurso à arbitragem do art. 21:3(c) do ESC em 39 ocasiões.

ESC, art. 21.5.

8 Já foram colocados em circulação 27 relatórios de painéis de implementação.

9 Anotam-se 19 notificações de pedido de apelação de relatórios de painéis de implementação, dos quais 16 já foram adotados pelo OSC.

${ }^{10}$ Registram-se atualmente 28 pedidos de autorização para retaliar no âmbito de 16 controvérsias distintas. Desse conjunto, 15 permissões foram concedidas, mas em apenas oito oportunidades, referentes a quatro controvérsias, sanções foram concretizadas.

11 ESC, art. 22.2, parte final.
} 
Para apreender o exato significado dessa expressão é preciso antes abordar as concessões e acordos subjacentes ao estabelecimento da OMC. A aquisição do status de Membro da entidade não decorre apenas da aquiescência do ingressante às regras existentes; além dessa condição primordial, é necessário, ainda, que o Membro em processo de acessão efetue um conjunto de concessões comerciais em favor dos participantes atuais (e.g. reduções tarifárias) em contraprestação aos benefícios que cada um deles lhe garantirá. ${ }^{12}$ Assim, no alicerce da OMC encontra-se um intrincado tabuleiro de concessões recíprocas meticulosamente negociadas entre seus Membros:

A state or independent customs territory does not become a WTO member simply in virtue of having signed myriad WTO agreements. An additional "entry fee" is required to become part of the WTO club. This "entry fee" consists of a series of trade concessions -- tariff reductions, marketaccess commitments in respect of foreign services, and so on -- that have to be granted to existing WTO members. These concessions are in addition to the multilateral obligations set out in the WTO agreements. Membership is secured only after these concessions are accepted by existing members as balancing the concessions that they will be giving to the newcomer through WTO membership. Consequently, at the foundation of a member-member relationship lies a delicately negotiated balance not only of rights and obligations explicitly enshrined in WTO agreements, but also of trade concessions exchanged at entrance and through a series of subsequent trade rounds (PAUWELYN, 2000:339).

É nesse contexto de equilibrada balança de concessões mútuas que a peculiar noção de retaliação na OMC deve ser entendida. Portanto, quando uma parte é condenada em uma controvérsia e se recusa a cumprir a decisão da entidade, abre-se ao reclamante o direito de aplicar sanções, que se traduzem na suspensão, provisória, de algumas das obrigações ou concessões por ele previamente acordadas em benefício do Membro infrator. A prática do mecanismo da OMC oferece alguns elucidativos exemplos da concretização das sanções, como na controvérsia EC - Hormones (DS26 e DS48), em que Estados Unidos ("EUA") e Canadá impuseram tarifas adicionais de até cem por cento às importações de queijo roquefort, mostarda, foie gras, dentre outros artigos provenientes da Comunidade Européia (“CE").

Importa, por fim, esclarecer que as retaliações, conforme delineadas pela OMC, têm como escopo induzir o Membro renitente ao cumprimento da decisão

\footnotetext{
12 Não-obstante a explicação ter sido construída tomando como exemplo a acessão de um novo integrante à organização, o raciocínio também se aplica às Partes-contratantes originais do GATT e, posteriormente, aos Membros da OMC.
} 
da organização. Por esse motivo, elas somente são admissíveis temporariamente, como instrumentos para alcançar o objetivo supremo da adequação da conduta indevida às normas do sistema multilateral de comércio. Inexistiria, conforme tal lógica, o pretenso direito de buy out, isto é, a faculdade de escolha que os Membros teriam entre cumprir a decisão ou, ao revés, suportar retaliações. ${ }^{13}$

\subsection{Requisitos de aplicação}

Um dos grandes avanços do sistema de solução de controvérsias da OMC em face de seu predecessor, o General Agreement on Tariffs and Trade ("GATT"), consiste no direito assegurado aos seus Membros de aplicar sanções para instigar o cumprimento de decisões que lhe são favoráveis. ${ }^{14}$ Nesse sentido, os estudiosos da OMC referem-se simbolicamente às retaliações como as "garras e dentes" da entidade; ferramentas que a municiam de poder de coerção para estimular a implementação de suas recomendações. As sanções, contudo, não podem ser utilizadas arbitrariamente pelos contendores. Com efeito, outro difundido progresso consubstanciado no mecanismo de resolução de disputas da OMC foi o adensamento de sua juridicidade (LAFER, 1998:32), pelo qual se procurou reduzir o território ocupado pelas manifestações de poder como elemento dirigente de seu funcionamento, enfatizando, em contraste, o papel desempenhado por fórmulas e esquemas de direito. Orientada por esse espírito jurídico, a aplicação das retaliações foi condicionada à estrita observância de um conjunto de requisitos normativos.

Em primeiro lugar, como anotado acima, afigura-se necessário o decurso do prazo originalmente fixado para o cumprimento da decisão da OMC, sem que o Membro vencido lance mão das mudanças exigidas. $\mathrm{Na}$ hipótese de divergência quanto ao adimplemento, a questão poderá ser submetida à apreciação de um painel de

\footnotetext{
13 "If everybody believed that the rich and powerful countries could avoid their obligations to conform to the rules upon which traders rely for a measure of predictability and security by simply 'buying out' of those obligations through compensation or sustaining suspended obligations, then a considerable degree of credibility and fairness of the system would be diminished or lost. Both small countries and developing countries could then say that the DS system is of no interest to them because they do not have the power to 'buy out' but the 'big guys' do have that power, and if they exercised it regularly, they would undermine the predictability and security of the rules as they might apply to enterprises or individual entrepreneurs from small countries." (Jackson, 2004:120-121)

${ }^{14}$ Muito embora o GATT-1947 permitisse a suspensão de concessões ou outras obrigações, tal medida dependia do consenso de todas as suas Partes-contratantes, incluindo aquela que poderia ser alvo de sanções ("consenso positivo"). Por conseguinte, não se podia falar na existência de efetivo direito de retaliação, como corrobora o histórico de apenas uma autorização (Holanda em face dos EUA - Ver Determinação das Partes-contratantes em 8 de Novembro de 1952 - Netherlands Measures of Suspension of Obligations to the United States, BISD 1S/32-33). Com a OMC, presenciou-se a inversão da regra do consenso e a conseqüente consolidação do direito de retaliar, passando a ser necessária a convergência de todos os Membros, inclusive o potencial retaliador, para obstar a concessão de autorização ("consenso negativo").
} 
implementação. ${ }^{15}$ Caso esse painel entenda que as determinações do OSC não foram integralmente observadas, e nenhum acordo satisfatório de compensação seja concluído, a parte prejudicada poderá então requerer permissão ao OSC para aplicar sanções, indicando o montante e a forma em que pretende retaliar. ${ }^{16} \mathrm{O}$ valor solicitado deverá ser equivalente ao nível do prejuízo experimentado pelo reclamante, respeitando-se o postulado da proporcionalidade, proibitivo de sanções superiores ao mal sofrido. ${ }^{17}$ Além disso, o objeto do pedido deverá obedecer a uma gradação na aplicação de sanções, estabelecida em razão do setor e do acordo em que ocorreu a violação ao sistema multilateral de comércio: ${ }^{18}$

a) retaliação no mesmo acordo e setor;

b) retaliação no mesmo acordo, porém em setor distinto; e

c) retaliação em acordo distinto.

O ESC estrutura uma ordem de preferências decrescentes para as retaliações. Em regra, a suspensão de concessões ou outras obrigações deverá ocorrer em relação ao mesmo setor em que foi verificada a transgressão (item (a)). Porém, as circunstâncias do caso concreto podem demandar como resposta mais adequada retaliações em outras áreas. Nessa hipótese, abre-se a possibilidade - condicionada ao preenchimento de um conjunto de requisitos, melhor explorados a seguir - de aplicar sanções em um setor distinto, compreendido no mesmo acordo em que a infração foi perpetrada (item (b)), ou, em última instância, em um acordo diverso (item (c)). Enquanto a hipótese descrita no item (a) poderia ser batizada de "retaliação convencional" ou "horizontal", as demais situações são comumente referidas na doutrina como "retaliações cruzadas".

O conjunto dessas normas deixa clara a necessidade de proporcionalidade entre a sanção e o dano, bem como a existência de uma relação de hierarquia entre os diferentes níveis de retaliação. Ambos elementos repontam como exigências para a autorização do direito de suspender concessões, tanto que, se o potencial destinatário das retaliações entender inexistentes quaisquer deles, abre-se-lhe a faculdade de submeter a análise do caso à arbitragem. ${ }^{19}$ Nessa hipótese, o mandato do procedimento arbitral se limitará à apreciação dessas duas questões e, sempre que possível, deverá ser conduzido pelos integrantes originais do painel; caso contrário, a indicação caberá ao diretor-geral da OMC. Em qualquer evento, o interregno para o deslinde da divergência é de 60 dias, contados do esgotamento do prazo razoável para a implementação da decisão, ficando

\footnotetext{
15 ESC, art. 21.5.

16 ESC, art. 22.2.

17 ESC, art. 22.4. "The level of the suspension of concessions or other obligations authorized by the DSB shall be equivalent to the level of the nullification or impairment".

18 ESC, art. 22.3.

19 ESC, art. 22.6.
} 
vedada, nesse ínterim, a aplicação de sanções. Além disso, cumpre estabelecer que a decisão da arbitragem é definitiva e inapelável. ${ }^{20}$

Em suma, o movimento de adensamento de juridicidade descrito pela OMC, ao mesmo tempo em que provem seu sistema de solução de controvérsias de mecanismos mais incisivos do que aqueles existentes no GATT, assegurando aos Membros a prerrogativa de aplicação de retaliações em caso de descumprimento de suas normas, também baliza o exercício de tal direito, de modo a evitar arbitrariedades por meio do seu condicionamento a uma série de requisitos legais, cujo atendimento poderá ser supervisionado por um procedimento arbitral a ser iniciado pela parte sancionada.

\section{Retaliação cruzada}

\subsection{Definição}

A retaliação cruzada pode ser definida como a suspensão de concessões ou outras obrigações em setores ou acordos distintos daqueles em que originalmente se verificou a infração às normas da $\mathrm{OMC} .{ }^{21}$ Conforme demonstrado acima, as regras de solução de controvérsias da entidade estabelecem um plano hierárquico na aplicação de suas sanções. ${ }^{22}$ Os alvos a serem retaliados não podem ser escolhidos arbitrariamente, devendo obedecer a alguns importantes parâmetros preestabelecidos. Nesse sentido, o princípio geral, encerrado no art. 22.3 (a) do ESC, determina uma correlação necessária entre a matéria violada e a respectiva área a ser afetada pelas sanções. Trata-se, como adiantado, das retaliações em sentido horizontal. Sem embargo, esse postulado não se mostra adequado a todas as situações, e, por conseguinte, foi prevista, nas alíneas (b) e (c), a possibilidade de retaliações cruzadas para alcançar setores distintos - de um mesmo acordo ou de um acordo diferente - daquele em que se deu a transgressão original.

\subsection{Definição de acordo e setor}

A compreensão da noção de retaliação cruzada reclama a exata definição dos acordos existentes na estrutura normativa da $\mathrm{OMC}$, bem como dos setores que permeiam

\footnotetext{
${ }^{20} \mathrm{ESC}$, art. 22.7.

${ }^{21}$ Outros tratados também contêm previsões sobre retaliações cruzadas, como é o caso do Acordo de Livre Comércio entre União Européia e México ("46.7. In considering what benefits to suspend, a complaining Party should first seek to suspend benefits in the same sector or sectors as that affected by the measure that the panel has found to violate the covered legal instruments. A complaining Party that considers it is not practicable or effective to suspend benefits in the same sector or sectors may suspend benefits in other sectors").

22 "The objective of this hierarchy is to minimize the chances of actions spilling over into unrelated sectors while at the same time allowing the actions to be effective" (OMC, 2004:98).
} 
cada um desses tratados. Com efeito, se a retaliação cruzada consiste em uma sanção em um setor, ou acordo, diferentes daqueles envolvidos na controvérsia, é necessária uma idéia nítida dessas delimitações. No que diz respeito ao significado do vocábulo "acordo", para fins de aplicação de retaliações, a alínea (f) do art. 22.3 do ESC estabelece três grandes conjuntos (bens, serviços e propriedade intelectual), identificando cada um deles como um acordo distinto:

(i) bens: compreende todos os tratados constantes do Anexo 1A do Acordo Constitutivo da OMC (GATT 1994, Acordo de Agricultura, Acordo sobre a Aplicação de Medidas Sanitárias e Fitossanitárias - SPS, Acordo sobre Têxteis e Vestuário, Acordo sobre Barreiras Técnicas ao Comércio TBT, Acordo sobre Medidas de Investimento relacionadas ao Comércio, Acordo de Antidumping, Acordo sobre Valoração Aduaneira, Acordo sobre Inspeção Pré-Embarque, Acordo sobre Regras de Origem, Acordo sobre o Procedimentos para o Licenciamento de Importações, Acordo sobre Subsídios e Medidas Compensatórias e o Acordo sobre Salvaguardas), bem como os acordos plurilaterais que integram o Anexo $4 ;^{23}$

(ii) serviços: abrange o Acordo Geral sobre o Comércio de Serviços (General Agreement on Trade in Services "GATS"), constante do Anexo 1B; e

(iii) direitos de propriedade intelectual: engloba o Acordo sobre Aspectos dos Direitos de Propriedade Intelectual relacionados ao Comércio (Trade-Related Aspects of Intellectual Property Rights - "TRIPS"), constante do Anexo 1C.

Além dessa primeira distinção, importa notar que a estrutura dos acordos acima discriminados pode compreender setores variados, cada qual com características próprias, extremamente relevantes quando da concretização das sanções. Nesse sentido, a alínea (f) do art. 22.3 do ESC também determina o significado do termo "setor":

(i) bens: tratados como um bloco indivisível, inexiste diferenciação de setores em seu âmago. Assim, não há que se falar em retaliações cruzadas para setores distintos dentro da área de bens, nem que se justificar com grandes artifícios a aplicação de sanções sobre produtos diversos daquele objeto da controvérsia. Em outros termos, uma disputa envolvendo carne bovina poderia, como de fato ocorreu em

\footnotetext{
${ }^{23}$ Ao contrário dos acordos multilaterais (Anexos 1, 2 e 3), que são obrigatórios, em toda a sua extensão, à totalidade de integrantes da OMC, os acordos plurilaterais só se aplicam aos Membros que optaram por sua assinatura. Integram o Anexo 4 o Acordo sobre o Comércio de Aeronaves Civis, o Acordo sobre Compras Governamentais, o Acordo Internacional de Carne Bovina, do qual o Brasil é signatário, e o Acordo Internacional dos Produtos Lácteos, extinto em 1997.
} 
EC-Hormones (DS26 e DS48), resultar em sanções sobre foie gras e queijo Roquefort, sem, contudo, extrapolar o âmbito das retaliações horizontais; ${ }^{24}$

(ii) serviços: segmentados em 11 setores, em consonância com a Lista de Classificação Setorial de Serviços da OMC atualmente em vigor (OMC, 1991):

1. serviços de empresas ("business services"): (i) serviços profissionais (v.g. serviços jurídicos, de contabilidade e auditoria, assessoramento tributário, arquitetura, engenharia, serviços médicos e odontológicos etc.); (ii) serviços de informática e conexos; (iii) serviços de pesquisas e desenvolvimento; (iv) serviços imobiliários; (v) serviços de arrendamento ou aluguel sem operador; e (vi) outros serviços de empresas (v.g. serviços de publicidade, serviços associados à agricultura, pesca, mineração, distribuição de energia, segurança etc.);

2. serviços de comunicação ("communication services"):

(i) serviços postais; (ii) serviços de correio; (iii) serviços de telecomunicações (v.g. serviços de telefonia, transmissão de dados, correio eletrônico, intercâmbio eletrônico de dados, processamento de dados e/ou informação online etc.); e (iv) serviços audiovisuais (serviços de produção e distribuição de filmes cinematográficos e fitas de vídeo, serviços de rádio e televisão etc.);

3. serviços de construção e de engenharia a eles relacionados ("construction and related engineering services");

4. serviços de distribuição ("distribution services");

5. serviços educacionais ("educational services"): serviços de ensino (i) primário; (ii) secundário; (iii) superior; (iv) de adultos; e (v) outros;

6. serviços de meio ambiente ("environmental services"): serviços de (i) esgoto; (ii) eliminação de desperdícios; e (iii) de saneamento e similares;

7. serviços financeiros ("financial services"): (i) serviços securitários e relacionados e (ii) serviços bancários e outros serviços financeiros;

8. serviços sociais e de saúde ("health related and social services"), excetos os médicos, odontológicos e veterinários;

9. serviços de turismo e relacionados com viagens ("tourism and travel related services"): (i) hotéis e restaurantes; (ii) serviços de agência de viagens e operadores de turismo; (iii) serviços de guias de turismo; e (iv) outros;

\footnotetext{
${ }^{24}$ Nessa esteira, o manual sobre solução de controvérsias preparado pelo Secretariado da OMC assevera que "a WTO-inconsistent tariff on automobiles (a good) can be countered with a tariff surcharge on cheese, furniture or pyjamas (also goods)" (OMC, 2004:98).
} 
10. serviços recreativos, culturais e desportivos ("recreational, cultural and sporting services"), exceto os serviços audiovisuais: (i) serviços de entretenimento, inclusive teatros, bandas de músicas e circos; (ii) serviços de agências de notícias; (iii) serviços de bibliotecas, arquivos, museus e outros serviços culturais; (iv) serviços desportivos e outros serviços de diversão; e (v) outros; e

11. serviços de transporte ("transport services"): (i) marítimo. (ii) por vias de navegação interior; (iii) aéreo; (iv) pelo espaço; (v) ferroviário; (vi) rodoviário; e (vii) por dutos.

(iii) direitos de propriedade intelectual: compreendem nove setores:

1. direito do autor e direitos conexos;

2. marcas;

3. indicações geográficas;

4. desenhos industriais;

5. patentes;

6. topografias de circuitos integrados;

7. proteção de informação confidencial;

8. obrigações contidas na Parte III do TRIPS, que trata da aplicação de normas de proteção dos direitos de PI; e

9. obrigações contidas na Parte IV do TRIPS, que regulamenta a obtenção e manutenção de direitos de PI e procedimentos inter-partes conexos.

\subsection{Hipóteses de cabimento}

A aplicação de retaliações cruzadas está condicionada à autorização do OSC, que deverá examinar se os requisitos inscritos no art. 22 do ESC foram devidamente cumpridos. ${ }^{25}$ A prescrição dessas exigências foi concebida para evitar sanções arbitrárias ou desproporcionais; contudo, também torna o seu acesso mais dificultoso a PEDs e países menos desenvolvidos ("PMDs"), porquanto lhes impõe a obrigação de comprovar a estrita observância dessas condições. Paradoxalmente, informam Subramanian e Watal (2000:410), ${ }^{26}$ a previsão desses princípios no conjunto normativo da OMC decorreu de pressão dos próprios PEDs, que, receosos de se tornarem alvos de retaliações cruzadas em

\footnotetext{
${ }^{25}$ Na prática, tal verificação é conduzida pela arbitragem do art. 22.6, comumente acionada pelo reclamado por discordar do pedido de retaliação feito pelo reclamante. Somente após tal apreciação é que mencionado pedido é submetido ao OSC, que deverá decidir se adota ou não as conclusões contidas no relatório da arbitragem.

26 "Paradoxically, in the Uruguay Round, it was the developing countries, fearing that cross-retaliation would be used against them to enforce obligations on TRIPS and GATS, which negotiated the present 'safeguards' into the DSU. As this paper implies, these 'safeguards' are of course counterproductive to their interests".
} 
bens por parte de PDs em busca de implementação de obrigações contidas no TRIPS ou GATS, reclamaram a inclusão de uma série de condições para a operacionalização de tal mecanismo.

Em sintonia com a existência de hierarquia entre os níveis de sanções, o primeiro requisito para a aplicação de retaliações cruzadas é a comprovação da impraticabilidade ou ineficácia da retaliação horizontal. Se a intenção do reclamante é suspender direitos ou obrigações em outro acordo, será preciso demonstrar ainda a ineficácia ou impraticabilidade de sanções em setores distintos do tratado violado. Na hipótese de transposição de acordo, um requisito adicional é imposto: as circunstâncias concretas devem ser suficientemente sérias. Em todos os cenários de retaliação cruzada, o pedido, além de motivado, deverá levar em consideração (i) o comércio relativo ao setor ou acordo no qual ocorreu a violação, (ii) a respectiva importância desse comércio para o reclamante, (iii) os elementos econômicos gerais decorrentes dessa transgressão e (iv) as conseqüências econômicas gerais da sanção almejada.

Ao dispor sobre esses requisitos, o ESC lança mão de expressões amplas, não oferecendo maior substrato para a definição de seu sentido. "Not practical", "[not] effective", "circumstances are serious enough", "broader economic elements" e "broader economic consequences" são locuções de significado aberto, que ensejam múltiplos entendimentos. Por conseguinte, o Membro que solicita retaliações cruzadas acaba detendo certa margem discricionária em sua apreciação, cuja adequação poderá ser supervisionada, mediante provocação, pelo sistema de solução de controvérsias da OMC. Assim sendo, e levando-se em conta a função guardiã e interpretativa da arbitragem do art. 22.6, tem-se que os relatórios dela resultantes afiguram-se como importante supedâneo para aclarar e precisar os delineamentos desses termos. ${ }^{27}$

A partir desses relatórios, e da análise dos dispositivos pertinentes do ESC, observa-se, inicialmente, ser desnecessária a cumulação dos requisitos de impraticabilidade e inefetividade, bastando comprovar a ocorrência de um deles (OMC, 2000A:18; OMC, 2007D:61). Assim, o ônus da prova para a parte que requer retaliações cruzadas se restringe, nesse tópico, à demonstração alternativa de impraticabilidade ou ineficácia de sanções no mesmo setor ou acordo. Tal imposição não se desdobra em uma obrigação positiva de se comprovar que a retaliação no setor ou acordo econômico pretendidos é praticável ou eficaz (OMC, 2000A:77-78; OMC, 2007D:61). Essa garantia é essencial para que PEDs e PMDs possam manejar retaliações cruzadas: visto que enfrentam dificuldades para implementar retaliações em qualquer setor ou acordo, ficam, ao menos, eximidos de uma carga de prova excessiva no sentido de demonstrar o êxito das sanções almejadas.

\footnotetext{
${ }^{27}$ Até o presente momento, apenas dois relatórios de arbitragem do art. 22.6 foram adotados pelo OSC: EC - Bananas III (Ecuador) e US - Gambling.
} 
Por impraticabilidade se entende uma sanção existente apenas no campo teórico, sendo impossível sua implementação no caso concreto (OMC, 2000A:18). ${ }^{28}$ Exemplificativamente, uma sanção em um setor em que o reclamado não exporta para o reclamante poderia ser considerada impraticável. Na disputa EC-Bananas III (Ecuador), foi declarada a impossibilidade de retaliação no setor violado (serviços de distribuição) com lastro na constatação de que o Equador não havia feito compromissos em seus subsetores. ${ }^{29}$ Além disso, o critério pode ser verificado pela análise dos custos que a medida acarreta para o mercado doméstico do retaliante - seja para os consumidores, seja para uso industrial como insumos, processamento ou outros (RUSE-KHAN, 2008:4). Por sua vez, o teste de efetividade consiste em examinar o grau de indução de uma retaliação, aferindo se, na prática, ela é capaz de levar o Membro recalcitrante a cumprir com celeridade as determinações adotadas pelo OSC. ${ }^{30}$ Interessante notar o reconhecimento na arbitragem $E C$ - Bananas III (Ecuador) de que em hipóteses envolvendo grande disparidade em relação ao tamanho do mercado e poder econômicos dos contendores ou forte relação de dependência entre eles (típica controvérsia PED versus PD), o exame da efetividade se traduz em identificar o setor ou acordo cuja retaliação seria menos gravosa ao reclamante. ${ }^{31}$ Nessa controvérsia, a aplicação de sanções sobre a importação de bens primários e de capital foi reputada ineficaz porque, além de representar uma fração irrisória das exportações totais da CE, implicaria aumento do custo de produção equatoriano (OMC, 2000A:2123). ${ }^{32} \mathrm{Na}$ mesma linha, em US - Gambling, mesmo sendo identificada a possibilidade de sanções em outros setores do GATS - acordo no qual ocorreu a infração -, concluiu-se por

28 “[...] an examination of the 'practicability" of an alternative suspension concerns the question whether such an alternative is available for application in practice as well as suited for being used in a particular case".

${ }^{29}$ Exceto no sub-setor ("whosale trade services") no qual se encontrou a violação, em que já se havia comprovado a inefetividade de retaliação (OMC, 2000A:23).

30 '“...] the term 'effective' connotes 'powerful in effect', 'making a strong impression', 'having an effect or result'. Therefore, the thrust of this criterion empowers the party seeking suspension to ensure that the impact of that suspension is strong and has the desired result, namely to induce compliance by the Member which fails to bring WTO-inconsistent measures into compliance with DSB rulings within a reasonable period of time" (OMC, 2000A:18).

31 "One may ask whether this objective [to induce compliance] may ever be achieved in a situation where a great imbalance in terms of trade volume and economic power exists between the complaining party seeking suspension and the other party which has failed to bring WTO-inconsistent measures into compliance with WTO law. In such a case, and in situations where the complaining party is highly dependent on imports from the other party, it may happen that the suspension of certain concessions certain other obligations entails more harmful effects for the party seeking suspension than for the party. In these circumstances, a consideration by the complaining party in which sector or under which agreement suspension may be expected to be least harmful to itself would seem sufficient for us to find a consideration by the complaining party of the effectiveness criterion to be consistent with the requirement to follow the principles and procedures set forth in Article 22.3" (OMC, 2000A:18).

${ }^{32}$ Nessa mesma esteira, conclui-se que retaliações em serviços prestados no território equatoriano teriam um forte impacto negativo nos investimentos estrangeiros diretos endereçados para esse PED (OMC, 2000A:2326). 
sua ineficácia em razão da dependência de Antígua e Barbuda da importação de serviços de infra-estrutura (v.g. serviços de transporte, telecomunicações e financeiros), cuja interrupção ensejaria danos para sua economia e consumidores (OMC, 2007D:70-73).

Para a determinação do que se entende por circunstâncias suficientemente graves, os fatores indicados no art. 22.3(d) - comércio e importância do setor ou acordo transgredido e elementos e conseqüências econômicas gerais - repontam como importante pano de fundo para a análise. O nível de gravidade da situação exigido para a transposição de acordo pode ser atingido quando há considerável desnível entre o desenvolvimento econômico das partes, como asseverado nas controvérsias EC - Bananas III (Ecuador) e US - Gambling (OMC, 2000A:27; OMC, 2007D:74-75).

Esses fatores do art. 22.3(d) figuram como guidelines para a apreciação de todos os demais princípios referentes às retaliações cruzadas. No que concerne à consideração do comércio e respectiva relevância para o reclamante do setor ou acordo no qual se detectou a inobservância das normas da $\mathrm{OMC}$, posições relativamente distintas podem ser observadas. Em EC - Bananas III (Ecuador), os árbitros apontaram que tal exercício deveria ser conduzido primordialmente em relação às operações comerciais prejudicadas pela medida irregular, relegando o exame global do comércio de um setor ou acordo a papel subsidiário (OMC, 2000A:20). Já em US - Gambling, adotou-se interpretação mais ampla de que a apreciação do comércio do setor como um todo seria indispensável. Ademais, assinalou-se que a importância do comércio deve ser levada em conta não apenas para o reclamante, mas também para o reclamado (OMC, 2007D:62).

As conclusões resultantes da atuação de ambas arbitragens permitem ainda assentar que a expressão "broader economic elements" está ligada aos prejuízos experimentados pelo reclamante como decorrência da violação. No caso EC-Bananas III (Ecuador), a crise econômica por que passava o Equador foi interpretada como elemento pertinente (OMC, 2000A:28). Em US - Gambling, foram-no as considerações de ordem geral aduzidas por Antígua e Barbuda sobre o tamanho e dependência de importações de sua economia (OMC, 2007D:73). Por seu turno, a locução "broader economic consequences" faz referência aos reflexos da aplicação das sanções tanto para retaliador quanto para retaliado (OMC, 2007D:73). Novamente, a interpretação do requisito pode ser ilustrada pelas disputas EC - Bananas III (Ecuador) e US - Gambling, nas quais a desproporcionalidade econômica entre os contendores influenciou inteiramente a análise do pedido de retaliações cruzadas sob o argumento de que referidas sanções teriam, por um lado, repercussões imperceptíveis para CE e EUA e, por outro lado, implicações negativas para Equador e Antígua e Barbuda, respectivamente (OMC, 2000A:134-136; OMC, 2007D:73). A preocupação em preservar os interesses dos PEDs e ter em conta os impactos que eventuais retaliações possam ter para sua economia deflui não apenas das balizas elencadas no art. 22.3(d), mas estão em sintonia ainda com as determinações 
do art. $21.7^{33}$ e $21.8,{ }^{34}$ que devem orientar todo o exame de retaliações cruzadas quando houver um PED envolvido.

Por derradeiro, cumpre mencionar que é a parte que solicita retaliação cruzada que suporta o encargo de comprovar a concorrência das condições estabelecidas pelo art. 22 do ESC. Entretanto, ao apresentar razões hábeis a motivar seu pedido, o requerente atrai para si a procedência de seu pleito, transferindo ao reclamado o dever de desconstituíla por meio de evidências que indiquem que os princípios de mencionado dispositivo não foram observados ( $v . g$. que eventual retaliação no setor ou acordo infringido é praticável ou eficaz, ou que as circunstâncias não são sérias o bastante) (OMC, 2000A:18).

\section{Retaliação cruzada em PI}

\subsection{Direitos de PI}

Sob o título "direitos de propriedade intelectual", encontram-se, principalmente, bens intelectuais aos quais se atribui exclusividade. "Criações do espírito", ${ }^{35}$ invenções, desenhos industriais, indicações geográficas e marcas, entre outros, são juridicamente tratados como escassos, como se pertencessem ao mundo concreto; daí sua aproximação aos direitos de propriedade clássicos.

O controle jurídico sobre bens intelectuais, que se espraia de softwares a meios de reprodução de variedades vegetais, impede sua livre manipulação. A exclusividade conferida a uma tecnologia, uma composição musical ou uma denominação de origem é a resposta jurídica a um problema econômico: os bens intelectuais, não-exclusivos e nãoconcorrentes, poderiam ser livremente apropriados caso um direito de propriedade não garantisse a exclusão de seu exercício por terceiros (LANDES e POSNER, 2003).

Para que haja estímulo à atividade criativa, portanto, procura-se, com tais direitos, internalizar parte do benefício social decorrente dos bens intelectuais (LEMLEY, 2005). O incentivo a potenciais autores e inventores, com a possibilidade de retribuição pelo uso de suas criações, traria benefícios sociais claros, dinâmicos, representados pelo desenvolvimento de novos bens intelectuais. Com direitos de propriedade, incentivos estáveis responderiam pelo desenvolvimento econômico e social associado às indústrias

\footnotetext{
21.7. "If the matter is one which has been raised by a developing country Member, the DSB shall consider what further action it might take which would be appropriate to the circumstances".

34 21.8. "If the case is one brought by a developing country Member, in considering what appropriate action might be taken, the DSB shall take into account not only the trade coverage of measures complained of, but also their impact on the economy of developing country Members concerned".

${ }^{35}$ Rótulo que abarca as criações intelectuais protegidas por direitos autorais. Vide Lei 9.610/98, art. $7^{\circ}$.
} 
intensivas em tecnologia e cultura. ${ }^{36}$ Seriam pronunciados, nesse sentido, os ganhos sociais com o estímulo à criação de mais bens intelectuais, que se reverteria em enriquecimento econômico e cultural e aceleração tecnológica. ${ }^{37}$

Os agentes privados são vistos como protagonistas, nesse esteio, da inovação tecnológica e das manifestações no campo da estética. Titulares principais dos direitos de PI, a eles caberia o papel de empreendedores capazes de forjar, a partir de idéias, ativos intelectuais socialmente relevantes. A participação do Estado, fundamental para que os bens intelectuais recebam tratamento normativo condizente com sua importância, ${ }^{38}$ coordena-se com a atividade privada nos planos econômico, político e cultural. ${ }^{39}$

Note-se, ainda, que a mera criação de direitos de PI gera expectativas sobre eles e insinua a adoção, por agentes econômicos beneficiados ou prejudicados, de medidas não restritas a seu(s) mercado(s) de atuação regular. Empresas conscientes das instituições de mercado que se apresentam podem traçar estratégias que almejem a substituição ou a cristalização de determinados direitos. ${ }^{40}$ Embora as mudanças, no caso de direitos de PI já existentes, sejam facilitadas pelo fato de esses direitos serem constituídos como regras formais, sujeitas a intervenções técnico-jurídicas mais rápidas, são inevitáveis os atritos relativos à modificação, suspensão ou extinção desses direitos, assim como a movimentação dos agentes econômicos em direção a oportunidades advindas da mudança institucional, seja criadora, seja supressora de direitos (NORTH, 1990:391).

\subsection{Bens intelectuais e retaliação cruzada}

A suspensão e/ou a extinção de direitos de PI no âmbito de uma controvérsia, e em resposta ao inadimplemento de um determinado Membro, afetam agentes econômicos públicos e privados, em vista da diminuição ou mesmo anulação do valor de ativos

\footnotetext{
36 "The incentives that are built into the institutional framework play the decisive role in shaping the kinds of skills and knowledge that pay off" (North 1990:78).

37 Autores dos mais distintos matizes externam, porém, preocupação com os custos ínsitos aos direitos de propriedade intelectual, que superam aqueles atrelados a direitos de propriedade tradicionais; vide, por exemplo, Landes e Posner (2003:16-24), Lemley (2005) e Benkler (2006). Barbosa (2003) destaca, com referência às normas brasileiras, a essencialidade de limitações apropriadas para os direitos de propriedade intelectual.

${ }^{38}$ Landes e Posner (2003:415) apontam que "equating intellectual property rights to physical property rights overlooks the much greater governmental involvement in the former domain than in the latter, at least in a mature society in which almost all physical property is privately owned, so that almost all transactions involving such property are private".

39 "property rights and hence individual contracts are specified and enforced by political decision-making, but the structure of economic interests will also influence the political structure" (North, 1990:48).

40 "Strong exclusive rights increase the attractiveness of exclusive-rights-based strategies at the expense of nonproprietary strategies, whether market-based or nonmarket based. They also increase the value and attraction of consolidation of large inventories of existing information with new production" (Benkler, 2006:50).
} 
intangíveis. Essas sanções, direcionadas conforme os direitos que se pretendam modificar, enfrentam, porém, uma carência de precisão, ${ }^{41}$ tendo em vista que as normas sobre bens intelectuais se originam de vários Estados e estão imbricadas em múltiplos mercados.

Nos mais diversos países, patamares mínimos de proteção e reciprocidade marcam as diretrizes relativas aos direitos de PI. Sua internacionalização decorre de esforços de integração positiva, ou seja, implantação de mecanismos de governança que dêem estabilidade a tais mercados, muito além de simplesmente os aproximar por meio da derrubada de barreiras comerciais. ${ }^{42}$ Contudo, invariavelmente, as normas sobre bens intelectuais e sua disciplina detalhada competem aos Estados que integram o sistema multilateral de comércio, de sorte que requisitos e condições locais sejam atendidos com flexibilidade. Não existe um parâmetro rígido imposto nem pelas Convenções de Paris e de Berna, nem pelo TRIPS. As diferenças nas previsões nacionais sobre PI, portanto, podem ser significativas.

Às assimetrias concernentes à inserção de direitos de PI no plano internacional, no qual o encontro de jurisdições expõe a diversidade de ativos e de transações, soma-se uma característica própria dos bens intelectuais: sua relevância transversal para a vida dos mercados. Traduzidos por tecnologias, tais bens incidem sobre os meios de produção, criando, modificando e destruindo mercados, permitindo a exploração de nichos e impondo reorganizações produtivas (BENKLER, 2006:311-315). Sob roupagens culturais, os bens intelectuais influenciam as percepções dos consumidores e a competição de produtos em determinado mercado (que é mediada por marcas, propagandas protegidas por direitos autorais, desenhos industriais etc.). Alguns bens intelectuais, por fim, constituem tecnologias de transação, mormente associadas a comunicações e transportes, capazes de reduzir brutalmente custos de transação.

Por esses motivos, os direitos de PI têm duas particularidades se comparados às demais regras de liberalização comercial da OMC. Em primeiro lugar, raramente se vinculam a um único mercado ou grupo de produtores, como ocorre com tarifas sobre bens. Em segundo lugar, ainda que respeitem os princípios da nação mais favorecida e do tratamento nacional, previstos no TRIPS e nos principais tratados administrados pela Organização Mundial da Propriedade Intelectual (OMPI), tais direitos têm configurações

\footnotetext{
${ }^{41}$ Smith (2003:16), ao comentar o pedido de retaliação cruzada equatoriano contra as CE, discutido abaixo, põe em relevo o lado positivo da imprecisão inerente aos efeitos de se suspender ou "reduzir" direitos de propriedade intelectual: "Ecuador had always acknowledged that any use of TRIPS would be messy - one official likened it to 'using a shotgun to hit a precise target' - but part of the strategy's utility came from this very fact.."

${ }^{42}$ Fligstein (2005:195) esclarece: "As producers come to compete with each other on a global basis, they encounter problems in protecting property rights, issues of competition and cooperation, and the need for rules of exchange that facilitate trade. The demand for global market rules thus comes from global firms trying to create and stabilize regional and worldwide markets".
} 
diversas conforme a jurisdição, o que permite comparações e medidas voltadas a ativos similares, mas não equivalentes, de acordo com o Membro da OMC responsável pelas normas de sua edificação.

Com relação aos mercados relacionados à propriedade industrial, nota-se que os diferentes direitos que compõem esse grupo aproximam-se mais de algumas indústrias, conforme a importância da exclusividade que conferem a certos bens intelectuais e os modelos de negócio envolvidos. Topografias de circuitos integrados, por exemplo, têm conexão direta e evidente com semicondutores. Indicações geográficas, por outro lado, jungem-se a produtos alcoólicos e alimentícios, mas aplicam-se também a inúmeros outros produtos. Cultivares, aparentemente vinculados à agricultura, podem proteger também espécies vegetais utilizadas em quaisquer pesquisas científicas ou plantas ornamentais. Finalmente, patentes, softwares, desenhos industriais e direitos autorais não podem ser considerados atinentes a nenhum setor econômico específico - mesmo que patentes sejam especialmente importantes, por exemplo, para empresas farmacêuticas, ou direitos autorais para a indústria do entretenimento -, e marcas menos ainda, sendo requeridas por indivíduos e empresas responsáveis por atividades de qualquer intensidade tecnológica.

Diante da diversidade de normas e da pluralidade de mercados atingidos por uma eventual "suspensão de concessões" previstas no Acordo TRIPS, a retaliação cruzada em PI pode ter muitos significados. Planejada minuciosamente, ela pode impactar menos agentes econômicos, ferir menos normas nacionais (do país ou território demandante) e internacionais e irradiar efeitos controlados e direcionados. Utilizada como trunfo em negociações, pode alavancar a composição das partes envolvidas em contenciosos comerciais. Todavia, evocá-la sem precaução pode acirrar o antagonismo dos litígios comerciais ou representar um simulacro de solução.

Passa-se, a seguir, à análise dos casos da OMC em que a retaliação cruzada em PI foi requerida. À luz desses contenciosos, procurar-se-á delinear os méritos e fragilidades dessa forma de retaliação, com atenção às necessidades dos PEDs.

\subsection{Analise casuística: EC - Bananas III (Ecuador), US - Upland Cotton e US - Gambling}

Até o presente momento, retaliações cruzadas em PI foram requeridas em três contenciosos da OMC, na seguinte ordem cronológica: EC-Bananas III (Ecuador), US - Upland Cotton e US - Gambling. Nos dois primeiros, pediu-se a transposição de retaliações que, pelo art. 22:3(a) do ESC, seriam preferencialmente voltadas contra bens. No último caso, Antígua e Barbuda requereram substituição das retaliações em serviços, objeto do contencioso que resultou na condenação dos EUA. 
No caso EC-Bananas III (Ecuador), decidiu-se que o regime de importação, venda e distribuição de bananas da CE contrariava as normas do GATT e do GATS. O Equador, ao requerer a retaliação cruzada, reforçou sua condição de PED, descrevendo a importância da exportação de bananas para sua economia e a situação de crise por que passava na época. O país justificou a retaliação cruzada argüindo que retaliar a CE no mesmo setor ou acordo econômico do objeto da controvérsia seria impraticável (OMC, 1999:1-2).

O Equador não especificou a forma de retaliação, mas a requereu de maneira selecionada com relação aos direitos e aos países afetados:

Ecuador proposes to suspend concessions or obligations stemming from the trade-related intellectual property rights in the following categories set out in Part II of the TRIPS Agreement:

Section 1: Copyright and related rights, Article 14: Protection of performers, producers of phonograms (sound recordings) and broadcasting organizations

Section 3: Geographical indications

Section 4: Industrial designs

(...)

The suspension of concessions or other obligations will apply to the following EC member States: Austria, Belgium, Finland, France, Germany, Greece, Ireland, Italy, Luxembourg, Portugal, Spain, Sweden and the United Kingdom. (OMC, 1999:3)

Essa escolha de alvos - "jurídicos" delimitados e de alguns Membros da $\mathrm{CE}$ - foi extremamente cuidadosa: não envolveu os países que haviam sido contrários à manutenção do regime de bananas contestado na OMC (Holanda e Dinamarca) e concentrou as sanções em direitos específicos, sensíveis para indústrias vocais dos países europeus afetados. Com isso, o Equador almejou autorização para um esquema retaliatório que não prejudicasse sua economia, recaindo principalmente sobre bens de consumo supérfluos, e que transmitisse uma mensagem política clara aos defensores do regime europeu de bananas. ${ }^{43}$

Além disso, o Equador propôs que as autorizações para violar o TRIPS fossem concedidas na forma de licenças temporárias, facilmente revogáveis, de modo que se pudesse controlar os efeitos de tais licenças (inclusive o quantum de prejuízo causado à

\footnotetext{
43 "Ecuador was careful to restrict its targets to categories of intellectual property in which there was little or no technology transfer, so as not to jeopardize its access to valuable technologies. Music and alcohol, after all, are the functional equivalent of consumer non-durables in the context of intellectual property". (Smith, 2003:15)
} 
$\mathrm{CE}$ ), ou mesmo suspender imediatamente essas medidas se a CE modificasse seu regime para bananas.

Em sua decisão referente ao pedido de retaliação equatoriano, os árbitros alertaram o Equador de que qualquer suspensão de direitos previstos pelo TRIPS poderia ser especialmente complexa, porque poderia (i) afetar simultaneamente titulares de direitos de várias nacionalidades, (ii) violar normas de tratados administrados pela OMPI, (iii) criar conflitos em mercados de terceiros países (nos quais determinados direitos manteriam seu império), e (iv) prejudicar agentes privados em diversos locais (OMC, 2000A:29-33). O plano de ação equatoriano, de todo modo, foi avalizado e mesmo elogiado, especialmente no que diz respeito à supervisão governamental por meio de licenças temporárias. ${ }^{44} \mathrm{Na}$ seqüência, o Equador preparou uma lista de produtos não-duráveis provenientes da Europa que seriam afetados pela retaliação, indicando também que ela só seria aplicada aos países selecionados em seu pedido de retaliação (OMC, 2000B).

Essa arbitragem, evidentemente, teve enorme repercussão. Na reunião do OSC que a sucedeu, inúmeros países manifestaram sua aprovação à chancela para que ocorresse retaliação cruzada, notando que garantias fortes do ESC eram fundamentais para que as controvérsias na OMC fossem realmente pacificadas. ${ }^{45}$ Em julho de 2001, as partes alcançaram solução amistosa (OMC, 2001); o contencioso, porém, continua a se desenrolar, inclusive com requerimento de instalação de novo painel, nos termos do art. 21.5 do ESC, para aferir a compatibilidade com a OMC das modificações ao regime de importação de bananas da CE (OMC, 2007B). Durante todo esse período, o Equador jamais implementou a autorização concedida para suspender concessões outras obrigações em PI.

Na controvérsia US - Upland Cotton, o OA concluiu que os subsídios estadunidenses ao algodão contestados pelo Brasil feriam as normas pertinentes da OMC (de seu Acordo sobre Agricultura e Acordo sobre Subsídios e Medidas Compensatórias). Antes da determinação final sobre o valor correspondente à suspensão de concessões ou outras obrigações, o Brasil manifestou interesse em retaliar em serviços e em PI. Ao formular

\footnotetext{
${ }^{44}$ Os árbitros apresentaram comentários específicos com relação à proposta de retaliação do Equador, tratando separadamente da suspensão de concessões referente a fonogramas, indicações geográficas e desenhos industriais (OMC, 2000A:33-35).

${ }^{45}$ Ressaltam-se as falas dos representantes da Guatemala ("His country was glad to note that not only the dispute settlement procedure was available to developing countries, but that the drafters had considered the need for a suitable and effective solution to ensure that the results of such proceedings were not merely theoretical."), de Honduras ("Even those Members who could not withdraw tariff concessions because of their weak economies could take measures in other sectors. This had given some breathing space to the multilateral trading system.") e dos EUA ("One of the central elements of the Uruguay Round package was the ultimate right of a Member to cross-retaliate when it considered it necessary under Article 22.3 of the DSU. (...) in terms of the overall result, given the continued absence of a solution to the Bananas dispute, the United States welcomed any new developments that would lead the EC to comply with its WTO obligations.") (OMC, 2000C:9-11).
} 
seus pedidos de retaliação, tanto em face dos subsídios proibidos (em aproximadamente US\$ 3 bilhões) (OMC, 2005A), como dos subsídios acionáveis (em aproximadamente US\$ 1 bilhão) (OMC, 2005B), o Brasil reconheceu a indicação preferencial de retaliação no mesmo setor, por meio de tarifas relativas ao comércio de bens, mas justificou pleito de retaliação cruzada nos seguintes termos:

The suspension of concessions and other obligations corresponding to a value of approximately US\$ 3 billion wholly applied to the importation of US goods - which amounted to US\$11.3 billion in calendar year 2004 - is neither practicable nor effective for at least two reasons.

First, the imposition of additional import duties affects the costs of inputs and capital goods that are essential to productive chain of the Brazilian industry. As a developing country, Brazil cannot place itself at disadvantage when competing with foreign products both in the domestic and international markets. Second, the rise in import costs will inevitably have a significant negative impact on current efforts to control inflationary pressures. Given the asymmetries between the two economies, additional import duties would have a much greater negative impact on Brazil than on the United States.

Finally, in Brazil's view, the circumstances are serious enough to justify the imposition of appropriate countermeasures under other covered agreements. First, the gravity of the violation; namely, prohibited subsidies which Brazil estimates to amount to approximately US $\$ 3$ billion per year. Continuing non-compliance renders the circumstances serious enough to make a case of imposition of appropriate countermeasures under another Agreement. [...] In addition to this, circumstances must be considered serious given the fact that Brazilian producers of upland cotton will continue to suffer serious losses while the United States does not withdraw the measures at issue (OMC, 2005A:2). ${ }^{46}$

Como fizera o Equador, o Brasil não especificou a forma de retaliação, embora tenha indicado que poderia,

to the extent necessary, resort to countermeasures in the form of suspension of obligations under the following sections of Part II of the Agreement on Trade-Related Aspects of Intellectual Property Rights:

Section 1: Copyright and related rights

Section 2: Trademarks

\footnotetext{
${ }^{46}$ A justificativa para o pedido de retaliações cruzadas referentes aos subsídios acionáveis corre no mesmo sentido (OMC, 2005B:2).
} 
Section 4: Industrial designs

Section 5: Patents

Section 7: Protection of undisclosed information (OMC, 2005A:2-3; OMC, 2005B:2).

Ademais, o País listou setores de serviços nos quais seus compromissos do GATS poderiam também ser suspensos (serviços de empresas; serviços de comunicação; serviços de construção e de engenharia a eles relacionados; serviços de distribuição; serviços financeiros; serviços de turismo e relacionados com viagens; serviços de transporte) (OMC, 2005A:3; OMC, 2005B:2-3).

Se, por um lado, o precedente EC - Bananas III (Ecuador) serviu como modelo ao pedido brasileiro, por outro, a estratégia equatoriana não foi seguida, ao menos no estágio anterior ao resultado dos questionamentos acerca da implementação da decisão (art. 21.5 do ESC). O Brasil não delimitou de maneira transparente a forma de imposição das retaliações e não informou de antemão ao OSC o modo pelo qual controlará o quantum da potencial retaliação (e.g. com licenças temporárias ou controle de emissões de royalties pelo Banco Central). Certamente o País terá que explanar seu modus operandi ao notificar a OMC caso o desenrolar do litígio reclame retaliações concretas.

Em US - Gambling, decidiu-se que os impedimentos efetivados pelos EUA à oferta de serviços de jogos de azar e apostas online violavam os compromissos daquele país relativos à liberalização de tais serviços, sendo portanto contrários ao GATS. Os demandantes nesse contencioso, Antígua e Barbuda, requereram ao OSC, em junho de 2007, autorização para suspender concessões e obrigações não no item do GATS que havia sido analisado na disputa, ${ }^{47}$ mas em PI e serviços de comunicação (OMC, 2007C).

Os argumentos para esse pedido de retaliação cruzada partiram da constatação de que o país demandante, PMD, não possuía condições de estimular o cumprimento da decisão do OSC pelos EUA por meio de retaliações horizontais. Antígua e Barbuda lembraram, ademais, que a retaliação no mesmo setor era impossível, tendo em conta que, ao contrário dos EUA, não haviam se comprometido a liberalizar seus próprios serviços de jogos e apostas.

O pedido de retaliação cruzada foi exposto sucintamente:

For the reasons given above, Antigua and Barbuda intends to take countermeasures in the form of suspension of concessions and obligations under the following sections of Part II of the TRIPS:

Section 1: $\quad$ Copyright and related rights

Section 2: $\quad$ Trademarks

Section 4: $\quad$ Industrial designs

${ }^{47}$ Setor 10.D, "Serviços desportivos e outros serviços de diversão". 


\begin{abstract}
Section 5: Patents
Section 7: Protection of undisclosed information

(...)

Antigua and Barbuda may also suspend horizontal and/or sectoral concessions and obligations for the following sector contained in the Antigua Schedule:
\end{abstract}

2. Communication Services (OMC, 2007C:4)

O requerimento de Antígua e Barbuda para suspensão de concessões ou outras obrigações em PI seguiu à risca o modelo brasileiro do caso US - Upland Cotton. A opacidade referente à implementação da retaliação cruzada em PI não obstou que os árbitros chancelassem o pedido, notando que não estavam autorizados, nos termos do art. 22.7 do ESC, a considerar a "natureza" das obrigações a serem suspensas ("we must assess the level of the proposed suspension, rather than its form, against the level of nullification or impairment") (OMC, 2007D:77). Entretanto, o painel enfatizou:

At the same time, it is important that the form that is chosen
in order to enact the suspension is such as to ensure that
equivalence can and will be respected in the application of
the suspension, once authorized. The form should also be
transparent, so as to allow an assessment of whether the
level of suspension does not exceed the level of nullification.
We also note that the suspension of obligations under the
TRIPS Agreement may involve more complex means of
implementation than, for example, the imposition of higher
import duties on goods, and that the exact assessment of the
value of the rights affected by the suspension is also likely to
be more complex ${ }^{48}$ (OMC, 2007D:77).

Com isso, buscou-se antecipar a incerteza decorrente de eventual retaliação em PI, ao mesmo tempo em que se impulsionam as possibilidades de enforcement no OSC.

Por fim, vale notar que os Estados Unidos externaram preocupação, no âmbito dessa controvérsia, com o monitoramento de eventuais sanções em PI, sugerindo que a potencial deficiência de Antígua e Barbuda em prover mecanismos confiáveis para assegurar a suspensão de concessões ou outras obrigações em nível não superior ao autorizado pelo OSC deveria ser impeditiva de tal autorização. Malgrado a legitimidade da preocupação, no sentido de que sanções não devem extrapolar o valor arbitrado, estimulando o desrespeito aos direitos protegidos pela $\mathrm{OMC}$, os árbitros decidiram,

\footnotetext{
48 "This is illustrated well by the explanations provided by Ecuador in the EC-Bananas III (Ecuador) (Article $22.6-E C)$ case as to how it proposed to implement the proposed suspension of TRIPS obligations, including through the setting up of specific government-run schemes". [nota de rodapé original]
} 
com acerto, que tal elemento não era pertinente para o procedimento de autorização de retaliações cruzadas. Com efeito, trata-se de preocupação posterior à permissão para retaliar, que não pode ser erigida como obstáculo para sua efetivação. Nesse sentido, basta mencionar que o Membro autorizado a retaliar poderia simplesmente utilizar tal faculdade como fator de barganha em negociações, sem, no entanto, concretizá-la. Ademais, o ESC prevê mecanismos apropriados para lidar com situações de transgressão ao montante autorizado para retaliar.

\subsection{Vantagens da utilização para PEDs de retaliação em PI}

A produção de bens intelectuais é extremamente concentrada em alguns países, de sorte que o comércio internacional a eles relacionado não se pauta por dispersão geográfica marcante. ${ }^{49}$ Exemplificam essa concentração as exportações de tecnologia, que provêm majoritariamente dos EUA, da Europa Ocidental e do Japão. É generalizada a constatação de que "Rightholders are disproportionately located in a few industrialized countries" (OMC, 2007A:300). Por isso mesmo, fortalece-se a acusação de que harmonização normativa e novas regras sobre bens intelectuais servem ao interesse de agentes econômicos específicos, situados em PDs e maiores beneficiados dos rendimentos decorrentes da propriedade sobre bens intelectuais (BENKLER, 2006).

Nesse contexto, algumas simplificações do fluxo comercial relacionado à PI permitem uma avaliação do potencial da retaliação cruzada com sanções fundadas no Acordo TRIPS. Em primeiro lugar, pode dizer-se que a relevância da produção de bens intelectuais por PEDs é muito inferior à correspondente aos PDs - tanto no que diz respeito ao campo da tecnologia quanto ao do entretenimento. Em segundo lugar, propõe-se que os mercados consumidores de bens intelectuais são geograficamente difusos, e que sua exploração é capitaneada por PDs. Exemplos pujantes dessa segunda proposição podem ser observados nas indústrias cinematográfica, farmacêutica e fonográfica. Combinandose essas assertivas, sobressai-se o potencial das retaliações cruzadas sobre PI: ao mesmo tempo em que os PEDs podem aumentar, e não diminuir, o consumo de determinados bens, as perdas econômicas em empresas dos PDs tendem a ser mais vultosas, o que pode acarretar impactos diretos sobre o cumprimento das decisões do OSC. ${ }^{50}$

\footnotetext{
${ }^{49}$ OCDE (2007) associa indústrias intensivas em tecnologia e conhecimento ao comércio internacional, comparando as balanças de pagamentos tecnológicas dos países desenvolvidos e identificando produtos e serviços associados a altas tecnologias. Embora aponte que a distribuição da propriedade intelectual por indústrias e por setores tecnológicos específicos é semelhante em países distintos, retrata claramente a concentração simultânea da produção e da exportação de bens intelectuais em poucos países.

${ }^{50}$ A afirmação é corroborada por Hudec (2002:90), que entende que "In theory, at least, denying the intellectual property rights of foreign owners results in assets being made available to developing countries at cheaper prices, which is usually a benefit to economic development rather than a burden on it. Likewise, although the
} 
Justamente por conta da especificidade da retaliação em PI, os PEDs recebem dois benefícios imediatos: primeiro, a retaliação sobre direitos de PI permite a diminuição de determinados preços, ao contrário do que ocorre com o aumento de tarifas decorrentes de retaliação em bens e serviços. ${ }^{51} \mathrm{O}$ consumo dos produtos afetados pode aumentar, com efeitos positivos para a indústria cultural pelo simples fato de mais bens intelectuais estarem disponíveis, e com resultados variáveis no que diz respeito a tecnologias novas (cuja divulgação pode ser contida, se o regime de proteção ofertado pelo Estado em questão for visto como instável, ou aumentada, caso os titulares e postulantes a titulares tenham confiança na seletividade da retaliação). Em segundo lugar, como a retaliação sobre direitos de PI pode ser desenhada para provocar diminuição direta do bemestar predominantemente fora do território do Membro da OMC que retalia, essa sanção é capaz de estimular o cumprimento das normas da OMC pelo Membro retaliado, sem que se prejudique gravemente a economia do Membro demandante na controvérsia que originou a retaliação. Indiretamente, cumpre lembrar, podem surgir prejuízos decorrentes da diminuição de investimentos no Membro demandante, ou perdas econômicas para suas empresas que utilizem direitos de PI afetados pela retaliação.

Nesse sentido, a retaliação cruzada tem a vantagem de otimizar os elementos de prevenção e de retribuição das sanções da $\mathrm{OMC}$, pois ocasiona dano comercial efetivo ao Membro transgressor (cujas empresas não podem simplesmente desviar sua produção, como ocorreria no caso de retaliação por meio de tarifas), incitando-o ao cumprimento das normas da $\mathrm{OMC}^{52}$ e atuando como exemplo e intimidação para os demais Membros. ${ }^{53}$ Se o cumprimento das normas for induzido com sucesso pela efetivação das sanções, a autorização para retaliação cruzada cumpre sua finalidade precípua de valorização do sistema multilateral de comércio, fim este distinto das próprias sanções. ${ }^{54}$

\footnotetext{
amounts of retaliation in most cases will still be 'negligible', at this time in WTO's history the ripple effects of even small-scale denial of intellectual property protection could cause considerably more political discomfort than the usual small-scale case of trade retaliation".

51 "In the case of TRIPS retaliation, denying foreign IP rights, at least in the short run, results in assets being available at a lower price, i.e. has the opposite effect of a retaliatory tariff' (OMC, 2007A:285-nota239). A retaliação em serviços tende a "ter efetividade semelhante à da retaliação em bens" (Spadano, 2005:31-32).

52 ESC, art. 22.1. "Compensation and the suspension of concessions or other obligations are temporary measures available in the event that the recommendations and rulings are not implemented within a reasonable period of time. However, neither compensation nor the suspension of concessions or other obligations is preferred to full implementation of a recommendation to bring a measure into conformity with the covered agreements. Compensation is voluntary and, if granted, shall be consistent with the covered agreements". (grifos nossos)

53 Ademais, conforme Ruse-Khan (2008:3), se o regime nacional de proteção de determinados direitos de propriedade intelectual for considerado inadequado, o Membro que efetiva a retaliação pode buscar uma melhor modelagem, tendo em conta que "the ability to suspend TRIPS obligations can create positive welfare effects if the suspension is utilized to make policy space in areas where TRIPS imposes obligations beyond the level suited for the domestic needs of the retailing country."

${ }^{54} \mathrm{ESC}$, art. 3.4. "Recommendations or rulings made by the DSB shall be aimed at achieving a satisfactory settlement of the matter in accordance with the rights and obligations under this Understanding and under the
} 
O Membro condenado pelo OSC, por sua vez, pode ser ainda mais bem coagido a reformular suas normas restritivas ao comércio se efetivamente sofrer retaliação em PI. Quer, como já assinalado, porque suas empresas são diretamente afetadas, não tendo escolha relativa ao rendimento que teria no mercado do Membro demandante, quer porque o constrangimento interno resultante pode ser enorme, tendo em vista a sensibilidade política da pauta "propriedade intelectual" e a articulação e força dos setores dela dependentes. ${ }^{55}$

\subsection{Reflexos negativos da retaliação em PI}

A retaliação cruzada em PI, em contrapartida, é alvo de inúmeras críticas. Como as normas sobre bens intelectuais são mecanismos de governança comercial transversal, atuante em vários mercados, a criação de assimetrias, mesmo que temporárias, pode prejudicar Membros da OMC que não foram partes na controvérsia. ${ }^{56}$ Há dificuldades diversas para a seleção dos titulares de direito a serem afetados por retaliações, bem como prejuízo potencial a operações transfronteiriças complexas, tais como importações paralelas, ofertas por meio de comércio eletrônico e transações intermediadas por empresas de Membros da OMC alheios à controvérsia que culmina em retaliação. ${ }^{57}$

Outra ala de críticas sublinha que a retaliação sobre PI ameaça investimentos, tanto diretos ao país sancionador quanto voltados a grupos de países nos quais ele se inclua. Além dos fluxos financeiros, a transferência de tecnologia poderia ser comprometida.

covered agreements".

55 Subramanian e Watal (2000:407-408) apontam, como vantagem saliente da retaliação cruzada em TRIPS, "the ability to create lobbyists to pressure non-complying constituents to comply with their WTO obligations. The greater the punitive cost of IPR retaliation, the more likely that the affected party would be roused into action". Os autores acrescentam que, ao contrário da retaliação convencional, que atinge muitos fornecedores, a retaliação em TRIPS pode selecionar determinadas empresas, como ocorre em investigações antidumping, acentuando as chances de grupos de pressão atuarem no Membro sancionado em prol da conformação às normas da OMC.

${ }^{56}$ A existência desse risco foi detectada na arbitragem ocorrida na controvérsia EC - Bananas III (Ecuador), na qual se alertou; "[...] it is important to point out that, in the case of suspension of obligations under Article 14, as requested by Ecuador, there may be different right holders of the different rights related to phonograms and that these right holders do not necessarily all have the nationality, within the meaning of Article 1.3 of the TRIPS Agreement, of one of those 13 member States in question, even if the phonogram concerned has been produced in one of those member States. The performer having rights to a phonogram under Article 14 may be a non-national of these 13 member States, but the producer of the phonogram may be a national of those member States. Such complicated situations will have to be carefully considered by Ecuador in implementing the suspension of TRIPS obligations, if authorized by the DSB, so as not to adversely affect right holders who cannot be regarded as nationals of those 13 EC member States" (OMC, 2000A: 29-30).

57 Subramanian e Watal (2000:414) refutam categoricamente que esse seja um empecilho para a retaliação cruzada em propriedade intelectual por PEDs: "In our view, the sheer number of property rights granted to foreigners by a typical developing country in a post-TRIPS world would confer ample degrees of freedom to choose the appropriate targets where such difficulties would not arise." 
Ademais, algumas formas de sanção estariam naturalmente sujeitas a circunvenção, especialmente se voltadas à fixação de royalties ou ao controle de sua emissão, já que poderiam ser dribladas com a utilização de intermediários, com a manipulação de preços pelos "produtores" afetados ou com outros expedientes característicos de manobras de planejamento tributário.

Finalmente, no lugar de elementos de Direito Internacional e econômicos, que se manifestam principalmente na operacionalização da retaliação cruzada, ${ }^{58}$ sua crítica mais contundente recai sobre o rompimento de um dos princípios estruturais do Acordo TRIPS, do Tratamento Nacional, gravado em seu art. $3^{\circ}$. Além disso, consta do preâmblo do Acordo o reconhecimento de que "intellectual property rights are private rights". Desse modo, a arquitetura do TRIPS seria rompida, de um lado, pela discriminação inerente à retaliação em PI, e de outro pelo confronto entre direitos privados e autorizações para retaliar, ou seja, entre obrigações assumidas internamente pelo Estado e seus pleitos no plano multilateral. ${ }^{59}$

A dificuldade de implementar retaliações cruzadas, reconhecida pelos julgadores do OSC que se depararam com o tema, esbarra não apenas na fissura de direitos nacionais e na oposição entre as normas do TRIPS e a autorização do OSC, mas também em eventuais ilícitos de Direito Internacional Público, considerando-se a malha de tratados que lidam com PI. Alguns deles, referidos no TRIPS, dialogam com o sistema multilateral de comércio sem entraves, especialmente os administrados pela OMPI.

Ainda assim, há risco de a retaliação cruzada representar violação de um ou mais tratados. ${ }^{60}$ Isso acontecerá nos casos em que um país não Membro da OMC,

\footnotetext{
${ }^{58}$ A implementação de sanções em propriedade intelectual, além de previsões normativas precisas, deve enfrentar questões operacionais relevantes, não aprofundadas nesse momento. Incluem-se nesse grupo as precauções para que haja interessados na exploração dos direitos de propriedade intelectual "suspensos" (licenciados compulsoriamente, destinados ao domínio público etc.), e para que tais interessados não lidem com instabilidades jurídicas desnecessárias (Subramanian; Watal, 2000:408-409). Pode ser intricada, ainda, a elaboração jurídica das medidas de retaliação no plano interno, pois seu direcionamento a pessoas físicas e jurídicas que não têm sequer locus standi na OMC contrasta com o caráter de "sanção" que nelas pode ser reconhecido.

${ }^{59}$ As dificuldades relativas à legalidade, à eventual necessidade de processos administrativos e à maior sujeição ao Judiciário da retaliação em propriedade intelectual, se comparada à tradicional, em tarifas, são acompanhadas da menor discricionariedade do Executivo. Subramanian e Watal (2000:408) notaram, nesse sentido, que "If IP rights, once conferred through domestic legislation and pursuant to an act of parliament, are withdrawn, this can be challenged by the affected parties in the domestic courts as being illegal or even unconstitutional", assinalando também que "Private IPRs, granted through legislation, cannot so easily be withdrawn by the Executive."

${ }^{60}$ Charnovitz (2001:822) esclarece essa questão: "An additional problem with permitting the DSB to authorize a suspension of TRIPS is that the WTO may then undermine WIPO. It is one thing for the WTO to flout its own norms. But it is another thing, and worse, for the WTO to unglue the obligations of longtime multilateral treaties on intellectual property". O autor lembra que os árbitros de EC - Bananas III (Ecuador) "admitted that they could not release Ecuador from its treaty obligations outside the WTO, and pointed out that a suspension of TRIPS obligations interferes with private rights owned by natural or legal persons".
} 
mas signatário do tratado violado, reivindicar seu cumprimento, que é obrigatório para o Membro da OMC que aplicar a retaliação cruzada, nos termos do art. 30:4(b) da Convenção de Viena sobre Direito dos Tratados, de 1969. Na hipótese de conflito com outro tratado, multilateral ou bilateral, é importante que sejam avaliadas as exceções previstas em tais instrumentos, inclusive porque mecanismos de solução de controvérsias próprios podem ser implicados por uma decisão de retaliar fundada em disputa do OSC (RUSE-KHAN, 2008:6). Essa hipótese é pouco provável tendo em vista que são Membros da OMC a esmagadora maioria dos signatários dos tratados relevantes sobre PI, e que haveria pouco interesse por parte de um terceiro país em reclamar o cumprimento do tratado, expediente que traria benefícios substanciais apenas ao Membro da OMC retaliado. ${ }^{61}$

É de se notar, também, que o setor privado pode sancionar o país que apela para retaliações cruzadas. Essa possibilidade foi aventada, durante o caso EC-Bananas III (Ecuador), pela European Confederation of Spirits Producers, que chegou a se prontificar para tomar medidas agressivas contra o Equador caso fossem violadas indicações geográficas de seus Membros (SMITH, 2003:17). Um boicote a todas as exportações do país foi então proposto, assim como o uso de rótulos que identificassem produtos elaborados com recurso a direitos de PI tornados disponíveis por retaliação cruzada.

Finalmente, no que tange à facilidade de implementação das retaliações cruzadas pelos PEDs, cumpre relembrar que as medidas retaliatórias precisam ser mensuráveis, isto é, devem ser passíveis de quantificação econômica, de sorte que o quantum estabelecido pelo OSC seja respeitado. Nesse sentido, propostas de aproveitamento dinâmico de direitos de PI estão circunscritas pela necessidade de controles eficazes, especialmente nos casos de difusão facilitada de tecnologias ou obras intelectuais. ${ }^{62}$

\subsection{Propostas para revisão do ESC}

Neste tópico, pretende-se apresentar algumas propostas de revisão das regras de solução de controvérsias concernentes à aplicação de retaliações cruzadas. Curiosamente, a primeira delas, submetida pelo Paquistão em abril de 1999, em lugar de buscar maior efetividade na utilização desse instrumento, defendia sua supressão do texto do ESC (OMC, 1999). A posição refletia com nitidez os receios manifestados pelos PEDs durante

\footnotetext{
${ }^{61}$ A reclamação, ademais, não poderia ser dirigida ao OSC, e enfrentaria severos obstáculos para ser julgada e efetivada. Exemplificativamente, as disputas originadas da interpretação ou aplicação da Convenção de Paris, nos termos de seu art. 28, podem ser submetidas à Corte Internacional de Justiça - cf. <http://www.wipo. int/treaties/en/ip/paris/trtdocs_wo020.html\#P409_66408> Acesso em: 29 fev. 2008. No entanto, a maioria dos signatários da Convenção de Paris apresentou reserva quanto à jurisdição obrigatória da Corte; até hoje, nenhum caso diretamente relacionado com a Convenção de Paris foi a ela submetida.

${ }^{62}$ Ruse-Khan (2008:7) exemplifica essa questão imaginando a oferta pela Internet, por Antígua e Barbuda, de obras protegidas por direitos autorais detidos por cidadãos e empresas estadunidenses.
} 
a Rodada Uruguai no sentido de que as retaliações cruzadas serviriam precipuamente para garantir a aplicação de sanções pelos PDs contra o setor de bens dos PEDs, em hipóteses de controvérsias versando sobre serviços e PI. Assim sendo, o entendimento predominante entre os PEDs era o de que a suspensão de obrigações deveria ocorrer necessariamente no mesmo setor da violação. Tal interpretação ignorava as vantagens que as retaliações cruzadas poderiam trazer para os próprios PEDs, e foi totalmente abandonada apenas após o caso EC-Bananas III (Ecuador).

Prova dessa evolução na visão dos PEDs encontra-se na proposta sobre tratamento especial e diferenciado colocada em circulação em outubro de 2002 por um conjunto de representantes desses países, dentre eles o próprio Paquistão, tencionando facilitar a aplicação de retaliações cruzadas (OMC, 2002). ${ }^{63}$ Dentre as modificações contidas nesse documento, propunha-se a liberdade na escolha dos setores a serem retaliados pelos PEDs, sob a alegação de que as exigências delineadas no art. 22:3 do ESC (v.g. ineficácia ou impraticabilidade das sanções no setor ou acordo transgredido e suficiente seriedade das circunstâncias concretas) impunham-lhes um ônus excessivo. Por conseguinte, sugeriu-se uma emenda no ESC introduzindo um novo parágrafo 3 bis, que dispensaria os PEDs, quando em litígio com PDs, de cumprir tais requisitos:

Notwithstanding the principles and procedures contained in paragraph 3 , in a dispute in which the complaining party is a developing-country Member and the other party, which has failed to bring its measures into consistence with the Covered Agreements is a developed-country Member, the complainant shall have the right to seek authorization for suspension of concessions or other obligations with respect to any or all sectors under any covered agreements.

Essa linha de raciocínio foi reiterada, em fevereiro de 2003, por um novo documento, de teor semelhante, mas contendo ligeiras modificações na linguagem proposta para a adoção do tratamento especial e diferenciado para os PEDs: ${ }^{64}$

Notwithstanding the principles and procedures contained
in paragraph 3, in a dispute involving a developing country
Member as complaining party and a developed country
Member as a party complained against, the complaining
party shall have the right to seek authorization for
suspension of concessions or other obligations with respect
to any or all sectors under any covered agreements, if the
party complained against fails to bring its measures into

${ }^{63}$ Documento apresentado por Cuba, Honduras, Índia, Indonésia, Malásia, Paquistão, Sri Lanka, Tanzânia e Zimbábue.

${ }^{64}$ Documento apresentado por Cuba, Honduras, Índia, Jamaica, Malásia e República Dominicana. 
compliance with the rulings and recommendations of the DSB or a covered agreement. (OMC, 2003)

E, em julho de 2006, após debates e reflexões com lastro na proposição de 2003, a redação do dispositivo foi uma vez mais revisada, resultando em uma versão simplificada e objetiva, encerrada em documento divulgado restritamente entre os Membros da OMC e o Secretariado por iniciativa das delegações de Cuba, Egito, Índia, Malásia e Paquistão. Essa nova redação vem sendo utilizada como base para as negociações de revisão do ESC, em consonância com o parágrafo 30 da Agenda de Doha para o Desenvolvimento. Considerando a existência de uma relativa satisfatoriedade dos Membros em relação ao funcionamento do sistema de solução de controvérsias da OMC, e manifestações de receio em face de modificações profundas que possam ameaçar sua legitimidade, ${ }^{65}$ acredita-se que os resultados dessa empreitada não devem ser muito ambiciosos, colocando em dúvida a aceitação das propostas de modificação do instituto das retaliações cruzadas. ${ }^{66}$ Sem embargo dessa previsão, deve-se enaltecer os méritos da proposta no sentido de se permitir um recurso mais facilitado às retaliações cruzadas em PI por parte dos PEDs, incrementando o seu poder de indução ao cumprimento das decisões que lhe são favoráveis. ${ }^{67}$

\subsection{Projetos de Lei em trâmite no Congresso Nacional}

Tramitam na Câmara dos Deputados dois Projetos de Lei ("PL") voltados a garantir que retaliações cruzadas em PI, se aprovadas pelo OSC, possam ser efetivadas no Brasil.

O primeiro, PL n. 5.489/2005, ${ }^{68}$ de autoria do deputado Fernando Gabeira (PV/RJ), busca "estabelecer a suspensão temporária dos direitos patentários" nas hipóteses descritas acima. Para isso, o PL acrescenta um capítulo à Lei n. 9.279/96, ${ }^{69}$ e

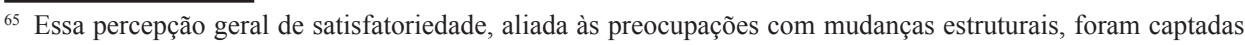
com precisão no Sutherland Report: "First, while there are some ground for criticism and reform on the dispute settlement system, as a whole, there exists much satisfaction with its practices and performance. Second, in appraising ideas for reform and improvement, the most important principle is to 'do no harm'. Caution and experience are needed before any dramatic changes are undertaken" (Sutherland, 2004:49).

${ }^{66}$ Sobre a ambição dos resultados dessas negociações, Davey (2006:9) entende que "although extensive proposals for changes have been made, there seems to be a general consensus that only limited modifications will be made".

${ }^{67}$ No mesmo sentido, Malacrida (2008:20-21) entende que na medida em que "this proposal would reduce the cost of retaliation and this reduction of cost would have a positive impact on developing country Members' willingness to retaliate, the proposal would make retaliation a more useful enforcement mechanism for this subset of Members".

${ }^{68}$ Disponível em <http://www.camara.gov.br/sileg/integras/318181.pdf > . Acesso em: 28/06/2008.

${ }^{69} \mathrm{O}$ acréscimo sugerido pelo PL introduziria o Capítulo VIII - A à Lei da Propriedade Industrial, "DA SUSPENSAÇÃO TEMPORÁRIA DA PATENTE"'(sic) (grifos nossos).
} 
estende as possibilidades de licenciamento compulsório do $\S 1^{\circ}$ do art. 68 desta lei, nelas incluindo "o descumprimento de compromissos assumidos" na OMC.

Sucinto e pouco preciso, o PL não define o significado do termo "suspensão", utiliza "direitos de propriedade industrial" e "patente" como sinônimos, vale-se do vocábulo "diluição" de maneira aleatória, erra a numeração da Lei n. 9.279/9670 e faz remissão a dispositivos legais inexistentes. ${ }^{71}$ Mais grave ainda, o PL sobrepõe, de forma opaca e despropositada, a possibilidade de "suspensão" determinada pelo Poder Executivoà nova modalidade de licenciamento compulsório, que teria iniciativa de qualquer particular. Contudo, o titular da patente a ser licenciada compulsoriamente precisaria, para que fosse dado azo a tal expediente, ter descumprido "compromissos assumidos na Organização Mundial do Comércio", o que é impossível, tendo em conta que tais compromissos são assumidos apenas pelos Estados e Territórios Membros da OMC.

A principal falha do PL é a não delimitação do alcance e do significado da sanção sofrida pelo titular da patente "suspendida". Apesar disso, é louvável a preocupação de restringir a retaliação conforme critérios do $\mathrm{ESC}$, o que é refletido no art. 74-A, $\S 2^{\circ}$, proposto para a Lei n. 9.279/96 com a seguinte redação:

A duração e extensão da suspensão e diluição desses direitos será limitada à duração do descumprimento da decisão da Organização Mundial do Comércio por parte do país inadimplente e do valor do prejuízo causado ao Brasil pela prática comercial lesiva.

O exame do PL pela Comissão de Desenvolvimento Econômico, Indústria e Comércio (CDEIC) culminou em parecer, adotado por unanimidade, pela rejeição do projeto, sob o argumento principal de que a proteção ao direito patentário é elencado pela Constituição como direito fundamental (art. $5^{\circ}$, XXIX). ${ }^{72}$ Desde abril de 2007, aguarda-se a deliberação de recurso para que o PL seja apreciado pelo Plenário da Câmara em razão do parecer contrário da CDEIC.

Em agosto de 2007, o deputado Paulo Teixeira (PT/SP) apresentou o PL 1893/2007. ${ }^{73}$ A preocupação com o uso ponderado e estratégico da retaliação cruzada espelha-se no caput do art. $5^{\circ}$ do PL, que faculta a administração alternada ou cumulativa

\footnotetext{
${ }^{70} \mathrm{O}$ art. $2^{\circ}$ do PL determina inovação no "art. 68, $\S 1^{\circ}$ da Lei 9.278, de 14 de maio de 1996" (sic) (grifos nossos).

${ }^{71} \mathrm{O}$ mesmo art. $2^{\circ}$ do PL ainda acrescenta à Lei da Propriedade Industrial inciso III ao art. 68, no qual consta a oração "nos termos do art. $3, \xi \xi 1^{\circ}, 2^{\circ}$ e $3^{\circ}$ desta lei”. Tais parágrafos inexistem.

72 Diário da Câmara dos Deputados de 22/12/06, p. 57079 COL 01, Letra A.

73 "Dispõe sobre medidas de suspensão e diluição temporárias ou extinção da proteção de direitos de propriedade intelectual no Brasil em caso de descumprimento de obrigações multilaterais por Estado estrangeiro no âmbito da Organização Mundial do Comércio.” Disponível em: <http://www.camara.gov.br/sileg/integras/497234. pdf $>$. Acesso em: 28 jun. 2008.
} 
das sanções descritas em seus incisos. ${ }^{74}$ Outro aspecto positivo do PL é a referência direta não apenas às normas do TRIPS, mas também à legislação nacional que concretiza as obrigações assumidas pelo Brasil na OMC. ${ }^{75}$

Embora sua acuidade técnica seja muito superior à do PL n. 5.489/2005, tal proposta também peca pela imprecisão conceitual. Destaca-se a referência, já no art. $1^{\circ}$ do PL, a "medidas de suspensão e diluição temporárias ou extinção de direitos de propriedade intelectual", sem que o projeto esclareça o significado dos termos "suspensão", "diluição" e mesmo "extinção", aparentemente auto-explicativo. Ademais, o uso do termo "Estado estrangeiro", nesse mesmo dispositivo, para se referir aos eventuais destinatários das sanções, não reflete com fidelidade todo o quadro de Membros da OMC, que além de Estados abrange outros "territórios aduaneiros autônomos", como Taipé Chinês ou Hong Kong. ${ }^{76}$ Também é incongruente a indicação, no art. $3^{\circ}$ do PL, de que pode ser suspendido "o cumprimento das obrigações e outras concessões das Partes II, III, e IV do Acordo TRIPS", mesmo que a Parte IV do TRIPS autorize os Estados a imporem obrigações para

\footnotetext{
${ }_{74}$ art. $5^{\circ}$ "Após comunicação do Ministério das Relações Exteriores sobre a decisão do OSC mencionada no dispositivo anterior, o Presidente da República decretará a suspensão, diluição ou extinção da proteção de direitos de propriedade intelectual de que trata a presente Lei, objetivando, alternada ou cumulativamente: I- rejeição temporária de pedidos de registro de direitos de propriedade intelectual depositados por titulares mencionados no 'caput' do art. $3^{\circ}$, quando tais direitos dependerem de ato registral da autoridade administrativa competente no território nacional;

II- interrupção temporária do procedimento de análise de pedidos de registro de direitos de propriedade intelectual que já tenham sido depositados perante a autoridade administrativa competente pelos titulares referidos no 'caput' do art. $3^{\circ}$;

III- bloqueio temporário de remessas de 'royalties'ao exterior e pagamento de assistência técnica, resultantes da exploração dos direitos de propriedade intelectual baseados em contratos vigentes concluídos entre os titulares referidos no 'caput' do art. $3^{\circ}$ e pessoas naturais ou jurídicas sediadas no território brasileiro;

$I V$ - licenciamento compulsório de direitos de propriedade intelectual dos titulares referidos no 'caput'do art. $3^{\circ}$

$V$ - incremento na retribuição devida aos órgãos públicos que realizam registros de direitos de propriedade intelectual ou registros relacionados à exploração econômica do objeto proteção da propriedade intelectual, de forma discriminatória desfavorável aos titulares mencionados no art. $3^{\circ}$, supra;

VI- não concessão de registro para explorar economicamente o objeto da proteção da propriedade intelectual;

VII- estabelecimento de domínio público temporário dos direitos de propriedade intelectual na vigência do periodo definido no art. $6^{\circ}$, infra.

VIII- extinção de direitos de propriedade intelectual, decretada no período definido no art. $6^{\circ}$, infra".

${ }^{75} \mathrm{O}$ art. $3^{\circ}$ do PL dispõe que "O Poder Executivo Federal poderá suspender, temporariamente, o cumprimento das obrigações e outras concessões das Partes II, III, e IV do Acordo TRIPS e da respectiva legislação nacional que trata da mesma matéria no que se refere à proteção de direitos de propriedade intelectual de titulares, pessoas naturais nacionais ou domiciliadas em determinado Estado, ou pessoas jurídicas domiciliadas ou com estabelecimento efetivo em determinado Estado, quando este tenha deixado de implementar decisões e recomendações do Órgão de Solução de Controvérsias da OMC em detrimento de legítimos interesses comerciais do Estado brasileiro". (grifos nossos).

${ }^{76}$ Uma alternativa para corrigir tal deficiência seria acrescentar, no corpo do art. $2^{\circ}$, definição, para os efeitos da presente Lei, de Estado como todos os países e territórios aduaneiros autônomos Membros da OMC, na esteira do que determinam as Notas Explicativas do Acordo Constitutivo da OMC.
} 
a aquisição dos direitos de PI, ou seja, ônus para seus titulares (e não direitos que poderiam ser suspensos como forma de sanção). ${ }^{77}$

O principal ponto a ser aprimorado, porém, é o modo de implementação das retaliações em PI. Duas das oito sanções propostas no art. $5^{\circ}$ do PL podem ser aplicadas sem reparos, desde que sigam o devido processo legal e respeitem os limites do art. 22:4 e 22:8 do ESC: o bloqueio de remessas de royalties e pagamentos de assistência técnica (inciso III) e o aumento dos encargos relativos ao registro de novos direitos de PI (inciso V). As demais esbarram em obrigações de Direito Internacional Público e nas proteções constitucionais aos autores e inventores.

Tendo em vista que a retaliação cruzada precisa limitar-se temporal e financeiramente aos prejuízos sofridos pelo Membro da OMC responsável por sua efetivação, são inviáveis, apenas da análise do ESC, três sanções previstas no referido artigo: (i) "rejeição temporária de pedidos de registro" (inciso I), (ii) "interrupção temporária do procedimento de análise de pedidos de registro" (inciso II) e (iii) "nãoconcessão de registro de direitos de propriedade intelectual" (inciso VI). Nesses três casos, o regime brasileiro de constituição de direitos pelo registro imporia aos postulantes da proteção rejeitada ou protelada a perda da prioridade, que na prática pode resultar na inexistência de direitos futuros. ${ }^{78}$ Pode-se acrescentar, ainda, que uma pretensa sanção que apenas atrase a concessão de determinado direito não será entendida como retaliação pelos agentes privados afetados, pois muitos registros de PI são normalmente morosos (SUBRAMANIAN; WATAL, 2000:412). Por sua vez, o licenciamento compulsório previsto no inciso IV do dispositivo sob exame, embora possível, precisaria ser balizado por procedimentos mais bem definidos - o que pode ser resolvido facilmente com seu atrelamento às normas detalhadas sobre licenciamento compulsório da Lei n. 9.279/96. Por fim, as duas sanções remanescentes, previstas nos incisos VII e VIII, padecem de uma mesma contradição lógica, ao pretenderem que exista "domínio público temporário", ou "extinção de direitos de propriedade intelectual" com duração definida. Em ambos os casos, fragiliza-se a retaliação porque seus efeitos não podem ser aferidos com clareza, além de as gritas relativas à arbitrariedade e incerteza jurídica ganharem justificação. ${ }^{79}$

\footnotetext{
77 Referida imprecisão, vale lembrar, não é exclusividade do PL em questão, mas deriva do próprio ESC, que em seu art. 22:3(f) (iii) prevê a suposta possibilidade de se implementar retaliações cruzadas em propriedade intelectual por meio da suspensão das obrigações contidas na Parte IV do TRIPS.

${ }^{78}$ Embora se possa, para fins retóricos, sustentar que apenas expectativas de direito seriam atingidas, na prática patentes, marcas, desenhos industriais e outros direitos dependentes de registro seriam obliterados, sem a devida mensuração do significado econômico de sua neutralização. Subramanian e Watal (2000:412) atentaram para esse problema, asseverando que "non-acceptance of applications must not result in loss of priority rights, as in that case the punitive measures would result in a loss of IP rights over the entire duration of the right, which may not be proportional to the nullification and impairment that is sought to be compensated".

${ }^{79}$ Saliente-se que a incerteza jurídica não recai apenas sobre os titulares dos direitos "extintos" ou colocados em "domínio público temporário", mas também sobre os terceiros de boa fé que se valham, por determinado
} 
Na seqüência, o PL procura estreitar as retaliações, impondo-lhes no caput do art. $6^{\circ}$ os limites ditados pelo art. 22 do ESC. ${ }^{80}$ Porém, no detalhamento do parágrafo primeiro, omite da duração da retaliação o teto referente ao valor da condenação pelo OSC. ${ }^{81}$ Ademais, o PL sugere estar impedida a cobrança retroativa ou futura, de qualquer valor, a qualquer título, relativa à exploração econômica no Brasil do objeto dos direitos de propriedade intelectual; ao uso, sem autorização do titular dos direitos, do objeto dos direitos de propriedade intelectual; ou a qualquer ato praticado com fundamento no art. $5^{\circ}$ desta Lei $\left(\operatorname{art.} 6^{\circ}, \S 2^{\circ}\right)$.

Essa prescrição, válida para todas as sanções acima discutidas, choca-se frontalmente contra diversas normas constitucionais brasileiras. ${ }^{82}$ Além disso, contraria os tratados internacionais sobre PI recepcionados pela legislação brasileira, ao admitir a expropriação de direitos sem remuneração a seu titular.

Ao contrário do PL n. 5.489/2005, o PL ora sob comento foi aprovado por unanimidade pela Comissão de Agricultura, Pecuária, Abastecimento e Desenvolvimento Rural (CAPADR $)^{83}$ e recebeu parecer favorável a sua aprovação pelo relator da CDEIC. ${ }^{84 / 85}$ Os motivos externados são de que referido PL opera em sintonia com os interesses comerciais e econômicos brasileiros:

Sua aprovação significa dotar o País de um instrumento de pressão comercial que permita acelerar a implementação pelo Estado infrator da solução estabelecida pela OMC, ante a possibilidade de seus agentes econômicos privados sofrerem prejuízos importantes. Trata-se, portanto, de norma que promove rapidez no restabelecimento de equilíbrio adequado do comércio externo em situações limite de desrespeito a decisões de ente público internacional (CÂMARA DOS DEPUTADOS, 2008:6).

Apesar dos problemas a serem corrigidos e dos obstáculos a serem enfrentados durante sua tramitação, ambos os projetos examinados têm o mérito de prenunciar situações de retaliação cruzada, que podem ocorrer num futuro próximo, por

período, dos bens intelectuais cuja proteção foi "temporariamente extinta", e que podem deparar-se com a "ressurreição" de uma exclusividade jurídica que não impedia suas atividades.

${ }^{80}$ Tais limites referem-se à "duração do descumprimento das obrigações multilaterais por parte do Estado vencido no procedimento de reclamação instaurado na Organização Mundial do Comércio e ao valor dos prejuízos por aquele causado aos legitimos interesses comerciais brasileiros", nos termos do art. $6^{\circ}$, caput, do PL.

${ }^{81}$ art. 22:4. "The level of the suspension of concessions or other obligations authorized by the DSB shall be equivalent to the level of the nullification or impairment."

82 A título exemplificativo, mencione-se o art. 5, incisos XXVII, XXIX e XXXVI da Constituição Federal de 1988.

${ }^{83}$ Disponível em <http://www.camara.gov.br/sileg/Prop_Detalhe.asp?id=364818>. Acesso em: 28 jun. 2008.

${ }^{84}$ Deputado Miguel Côrrea Jr. (PT/MG).

85 Até julho de 2008 mencionado parecer ainda não fora objeto de votação por essa Comissão. Além da CDEIC e da CAPADR, o PL também deverá ser examinado, na Câmara dos Deputados, pela Comissão de Constituição, Justiça e Cidadania (CCJ). Ver <http://www.camara.gov.br/sileg/Prop_Detalhe.asp?id=364818>. Acesso em: 28 jun. 2008. 
exemplo no desenrolar do caso US - Upland Cotton. A preparação do quadro normativo brasileiro para essa eventualidade é fundamental. Previsão legal expressa dos efeitos de uma decisão do OSC favorável à retaliação cruzada é imprescindível, ressalte-se, para que seja lícita a interferência estatal sobre direitos assegurados por lei. ${ }^{86} \mathrm{Com}$ o devido cuidado, é possível e desejável que essa intervenção seja planejada e efetivada sem ofensa às garantias constitucionais a tais direitos - e, portanto, sem necessidade de alteração à própria Constituição.

Alternativa às sanções neles previstas seria a implementação da retaliação autorizada pelo OSC por meio do uso público não comercial de determinados direitos de PI, notadamente relacionados ao acesso a medicamentos, informação e cultura. Presente em diversas legislações, ${ }^{87}$ essa previsão permite o uso público não comercial, sem pagamento de royalties ao detentor, por exemplo, da patente sob uso público. O próprio TRIPS antecipa essa possibilidade em seus arts. 30 e 31.

\section{Conclusão}

A noção de retaliação cruzada foi concebida durante a Rodada Uruguai, fruto dos esforços dos PDs em assegurar a efetividade de suas sanções em controvérsias envolvendo serviços ou direitos de PI. Partindo da constatação de que PEDs, em regra, somente poderiam ser eficazmente retaliados em bens, devido ao insignificante volume de seu comércio de serviços, ou por serem detentores menos vistosos de direitos de PI, os PDs concluíram ser necessário prever a possibilidade de retaliações em acordos distintos daquele em que foi detectada a violação (HUDEC, 2002:89). Almejavam, com isso, estender as sanções ao comércio de bens dos PEDs em disputas versando sobre disposições do GATS ou TRIPS. Os PEDs, incluindo o Brasil, opuseram-se de maneira ferrenha à proposição, mas não conseguiram evitar que ela se tornasse parte integrante das normas de solução de conflitos da OMC (MALACRIDA, 2008:20).

Apesar desse início ominoso, a prática do mecanismo de solução de controvérsias da OMC demonstrou que o instituto da retaliação cruzada poderia, curiosamente, servir aos interesses dos PEDs. Foram necessários alguns anos até que esses

\footnotetext{
86 "The main obstacle to using TRIPS as a weapon of trade retaliation may not lie in the WTO, but in the fact that the domestic IP legislation, or drafts in process, of developing countries do not presently provide for this possibility." (Subramanian; Watal, 2000:415). "To suspend TRIPS obligations as a retaliatory measure, a Member will have to enact legislation which allows suspending IP rights to the extent authorized by the dispute settlement organs of the WTO. Such legislation must not only fit into the domestic legal system including constitutional and other statutory norms relating to IP, but further ensure that a suspension of IP protection is legal under WTO and other international obligations". (Ruse-Khan, 2008:6).

${ }^{87}$ Entre outros países, Cingapura, Reino Unido, Quênia e Gana permitem o uso público não comercial de patentes (UNCTAD-ICTSD, 2006:44-46).
} 
Membros vislumbrassem a possibilidade de utilizar o instrumento em sentido inverso, é dizer: efetivar sanções contra serviços ou PI de modo a estimular o cumprimento de decisões envolvendo o comércio de bens. ${ }^{88}$ Descobriu-se, assim, uma eficaz alternativa para o incremento da qualidade da atuação dos PEDs no foro de solução de controvérsias da entidade. Hoje, alguns desses países inclusive defendem alterações nas normas procedimentais da entidade para facilitar a utilização das retaliações cruzadas.

Como restou demonstrado, a limitada pauta comercial da maioria dos PEDs implica (i) enormes dificuldades para suspender concessões na área de bens em montante equivalente aos prejuízos sofridos; (ii) intensa dependência de importações, tornando inviável ou extremamente gravosa a aplicação de retaliações nos bens e serviços adquiridos do exterior; e (iii) irrelevância da representatividade de suas compras em relação ao volume total de comércio de bens e serviços do retaliado, tornando eventual sanção horizontal ineficaz. Diante desse cenário, verificado tanto em EC - Bananas III (Ecuador) como em US - Gambling, as retaliações cruzadas em PI emergem como alternativa viável, na maioria dos casos, para que PEDs busquem induzir o cumprimento de decisões que lhes são favoráveis. Isso porque permitiriam a efetivação da integralidade do valor autorizado para as retaliações, sem interromper ou onerar o fluxo de bens importados essenciais, além de causarem maior desconforto para o retaliado. ${ }^{89}$

Outro mérito das retaliações cruzadas em PI consiste no fato de que sua utilização prescinde de alteração das normas internacionais vigentes, porquanto já expressamente autorizada pelo texto do ESC. Em um momento em que a rodada de negociações na OMC atravessa uma fase sensível, e que importância subsidiária é conferida à revisão das regras de solução de controvérsias, tidas como relativamente satisfatórias, a existência dessa ferramenta no corpo normativo da OMC deve ser aproveitada. Em que pesem inúmeras - e muitas vezes pertinentes - críticas às retaliações cruzadas, como aquelas apontadas no item 5.5, é necessária uma visão pragmática a seu respeito. Não se trata de um instituto isento de falhas; há deficiências, porém, em todas as medidas de indução ao cumprimento, atuais e futuras. Assim, é recomendável seu manejo em favor dos interesses dos PEDs até mesmo para testar seus resultados práticos, vez que até o momento, em que pese sua autorização em duas ocasiões, as retaliações cruzadas em PI ainda não foram concretizadas.

A oportunidade para tanto pode não estar distante. Recentemente, o $\mathrm{OA}$ concluiu que os EUA não cumpriram as determinações da OMC no caso US - Upland

\footnotetext{
${ }^{88}$ Como discutido no item 5.5 acima, a retaliação em serviços, horizontal ou cruzada, tende a ser muito pouco atraente para os PEDs, por produzir efeitos similares aos decorrentes da retaliação em bens.

89 Nessa mesma esteira, constata Amaral Júnior (2007:96) que "Tendo em vista a restrita pauta de exportações dos PEDs, a alternativa de retaliações cruzadas torna o mecanismo da retaliação mais eficiente e também pode limitar seus impactos negativos sobre a pauta de importações e a economia desses países".
} 
Cotton (OMC, 2008), abrindo caminho para que o Brasil solicite permissão para aplicar sanções com vistas a impelir o cumprimento da decisão (v.g. eliminação, pelos EUA, dos subsídios proibidos e dos efeitos prejudiciais dos subsídios acionáveis). Desde 2005, o Governo brasileiro vem acenando com a intenção de recorrer a retaliações cruzadas em PI e, agora, seu pedido deverá ser apreciado pela organização. Todavia, o caminho ainda é intrincado, com complexos obstáculos de ordem jurídica e política.

Preliminarmente, um procedimento arbitral (art. 22.6 do ESC) deverá ser instalado para aferir o montante das retaliações e determinar os setores em que elas poderão recair. Até agora, retaliações cruzadas somente foram aprovadas para países com limitada inserção no comércio internacional (Equador e Antígua e Barbuda). Essa será a primeira vez em que o instituto será analisado sob o enfoque de um Membro da OMC que, embora classificado como PED, é reputado como um dos mais importantes players do cenário mundial, com expressivo volume de comércio. Nesse sentido esperamse contundentes argumentos contrários dos EUA, especialmente tendo em conta que a decisão final trará reflexos sistêmicos e se tornará paradigmática para a futura utilização de retaliações cruzadas por PEDs, que se prevê crescente..$^{90}$ Em todo caso, o êxito da medida estará condicionado ao valor arbitrado como parâmetro para a aplicação de sanções pelo Brasil e, acima de tudo, pela proporção desse total que será autorizada especificamente para suspensão de obrigações no âmbito do TRIPS.

Sem embargo, e mesmo diante de um cenário positivo em que ao Brasil seja conferido o direito de aplicar sanções em PI em um montante razoável, restarão inúmeras considerações acerca da oportunidade política do uso das retaliações e de seus eventuais efeitos colaterais..$^{91}$ Ademais, repontarão dificuldades sobre como implementar a retaliação, o que abrange questões que vão desde mudanças na esfera legislativa interna até indagações sobre quais direitos de PI serão escolhidos como alvo ${ }^{92}$ e de que forma será mensurado o impacto econômico da suspensão de obrigações. De qualquer maneira, cumpre ressaltar que a mera autorização para retaliar já aumenta a pressão sobre os EUA para adequação de sua conduta, bem como aumenta o poder de barganha do Brasil para

\footnotetext{
90 "Since suspension of intellectual property commitments under the TRIPS agreement is likely to be a boon to developing countries regardless of the nature of the dispute, we should expect more developing countries to seek to use the cross-retaliation remedy". (Nzelibe, 2008:356).

91 "retaliatory suspension of TRIPS obligations is certainly legal in international law, but it may give rise to domestic legal battles. It can be feasible, but its implementation involves many technical difficulties that some developing countries, particularly smaller ones, might not be prepared to face. It may be effective and indeed it could lead to improved compliance, but that will largely depend on whether new authorizations are requested and obtained and successfully implemented" (Spadano, 2005:41, grifos no original).

92 A título exemplificativo, o presidente da Associação Brasileira dos Produtores de Algodão (Abrapa), Haroldo Rodrigues da Cunha, sugere a suspensão no pagamento de royalties sobre variedades de algodão (cultivares), insumos ou tecnologias de produção relacionados ao setor cotonicultor como maneira de fazer com que as sanções revertam em benefícios diretos para mencionado segmento (Valor Econômico, 2008).
} 
exigir mudanças na legislação estadunidense. Com algumas ressalvas, as conclusões externadas para a controvérsia do algodão podem ser estendidas para os demais casos envolvendo sanções por PEDs.

Em suma, diante do panorama atual, as retaliações cruzadas em PI surgem como alternativa interessante para incrementar a eficácia da participação dos PEDs no sistema de solução de controvérsias da $\mathrm{OMC}$, especialmente por sua incisiva contribuição no caráter de indução ao cumprimento das decisões que lhes são benéficas. Não-obstante, afigura-se sempre necessário buscar outras opções de atuação, pois, como adverte HUDEC (2002:90), nunca é aconselhável colocar todos os ovos em uma mesma cesta.

São Paulo, junho de 2008.

\section{Referências}

BARBOSA, Denis B. Uma introdução à propriedade intelectual. 2. ed. Rio de Janeiro: Lúmen Júris, 2003.

BENKLER, Yochai. The Wealth of Networks: how social production transforms markets and freedom. New Haven (EUA): Yale University Press, 2006.

CÂMARA DOS DEPUTADOS. Comissão de Desenvolvimento Econômico, Indústria e Comércio - Projeto de Lei n. 1.893, de 2007: parecer do Relator, Dep. Miguel Corrêa Jr. (PT-MG), pela aprovação. Disponível em: <http://www.camara.gov.br/sileg/integras/524860.pdf > . Acesso em: 28 jun. 2008.

CRETELLA NETO, José. 2002. Sistema processual de solução de controvérsias da OMC Organização Mundial do Comércio: casuística de interesse para o Brasil. São Paulo. Tese (Doutorado) - Faculdade de Direito, Universidade de São Paulo.

DAVEY, William J. 2006. The WTO: looking forwards. Journal of International Economic Law, v. 9, n. 1, p. 3-29, 2006.

FLIGSTEIN, Neil. The political and economic sociology of international economic agreements. In: SMELSER, Neil J.; SWEDBERG, Richard (eds.). The Handbook of Economic Sociology. 2. ed. New Jersey (EUA): Princeton University Press, 2005.

HUDEC, Robert. 2002. The adequacy of WTO dispute settlement remedies: a developing country perspective. In: HOEKMAN, Bernard; MATTOO, Aaditya; ENGLISH, Philip (eds.). Development, trade, and the WTO: a handbook. Washington, DC (EUA): World Bank, 2002. p. 81-91.

KECK, Alexander; SCHROPP, Simon. 2007. Indisputably Essential: The Economics of Dispute Settlement Institutions in Trade Agreements (September 2007). WTO Staff Working Paper N. ERSD-2007-02. Disponível em: <http://www.wto.org/english/res_e/reser_e/ersd200702_e.pdf>. Acesso em: 08 dez. 2007. 
LAFER, Celso. 1998. A OMC e a regulamentação do comércio internacional: uma visão brasileira. Porto Alegre: Livraria do Advogado, 1998.

LANDES, William M.; POSNER, Richard A. The economic structure of intellectual property law. Cambridge (EUA): Belknap, 2003.

LEMLEY, Mark. Property, intellectual property, and free riding. Texas Law Review, v. 83, p. 1.031$1.075,2005$.

MALACRIDA, Reto. Towards sounder and fairer WTO retaliations: suggestions for possible additional procedural rules governing members' preparation and adoption of retaliatory measures. Journal of World Trade, v. 42, n. 1, p. 3-60, 2008.

NORTH, Douglass C. Institutions, institutional change and economic performance. Cambridge (GBR): Cambridge University Press, 1990.

NZELIBE, Jide. 2008. The Case Against Reforming the WTO Enforcement Mechanism. University of Illinois Law Review, n. 1, p. 319-358, 2008.

OCDE. 2007. OECD Science, Technology and Industry: Scoreboard 2007. Paris (FRA): OCDE. Disponível em <http://caliban.sourceoecd.org/vl=2280175/cl=20/nw=1/rpsv/sti2007/index.htm> Acesso em: 06 jan. 2007.

OMC. 1991. MTN.GNS/W/120. SERVICES SECTORAL CLASSIFICATION LIST. 10 July 1991. Original: English / Restricted. Geneva: OMC.

OMC. 1999. WT/GC/W/162. GENERAL COUNCIL - PREPARATIONS FOR THE 1999 MINISTERIAL CONFERENCE: The Dispute Settlement Understanding (DSU) - Communication from Pakistan. 1 April 1999. Original: English. Geneva: OMC.

OMC. 2000A. WT/DS27/ARB/ECU. EUROPEAN COMMUNITIES - REGIME FOR THE IMPORTATION, SALE AND DISTRIBUTION OF BANANAS: Recourse to arbitration by the European Communities under Article 22.6 of the DSU - Decision by the Arbitrators. 24 March 2000. Original: English. Geneva: OMC.

OMC. 2000B. WT/DS27/54. EUROPEAN COMMUNITIES - REGIME FOR THE IMPORTATION, SALE AND DISTRIBUTION OF BANANAS: Recourse to Article 22.7 of the DSU by Ecuador. 8 May 2000. Original: English. Geneva: OMC.

OMC. 2000C. WT/DSB/M/78. DISPUTE SETTLEMENT BODY: Minutes of Meeting (Held in the Centre William Rappard on 7 April 2000). 12 May 2000. Original: English / Restricted. Geneva: OMC.

OMC. 2001. WT/DS27/58. EUROPEAN COMMUNITIES - REGIME FOR THE IMPORTATION, SALE AND DISTRIBUTION OF BANANAS: Notification of Mutually Agreed Solution. 2 July 2001. Original: English. Geneva: OMC. 
OMC. 2002. TN/DS/W/19. DISPUTE SETTLEMENT BODY: Special Session - Negotiations on the Dispute Settlement Understanding - Special and Differential Treatment for Developing Coutries - Proposals on DSU by Cuba, Honduras, India, Indonesia, Malaysia, Pakistan, Sri Lanka, Tanzania and Zimbabwe . 9 October 2002. Original: English. Geneva: OMC.

OMC. 2003. TN/DS/W/47. DISPUTE SETTLEMENT BODY: Special Session - Dispute Settlement Understanding Proposals - Legal Text - Communication from India on behalf of Cuba, Dominican Republic, Egypt, Honduras, Jamaica and Malaysia. 11 February 2002. Original: English. Geneva: OMC.

OMC. 2004. A handbook on the WTO dispute settlement system: a WTO Secretariat publication. Cambridge (GBR): Cambridge University Press.

OMC. 2005A. WT/DS267/21. UNITED STATES - SUBSIDIES ON UPLAND COTTON: Recourse to Article 4.10 of the SCM Agreement and Article 22.2 of the DSU by Brazil. 5 July 2005. Original: English. Geneva: OMC.

OMC. 2005B. WT/DS267/26. UNITED STATES - SUBSIDIES ON UPLAND COTTON: Recourse to Article 7.9 of the SCM Agreement and Article 22.2 of the DSU by Brazil. 7 October 2005. Original: English. Geneva: OMC.

OMC. 2007A. World trade report 2007: six decades of multilateral trade cooperation: what have we learnt?. Geneva: OMC. Disponível em < http://www.wto.org/english/res_e/booksp_e/anrep_e/ world_trade_report07_e.pdf $>$ Acesso em: 06 dez. 2007.

OMC. 2007B. WT/DS27/80. EUROPEAN COMMUNITIES - REGIME FOR THE IMPORTATION, SALE AND DISTRIBUTION OF BANANAS: Recourse to article 21.5 of the DSU by Ecuador Request for the Establishment of a Panel. 27 February 2007. Original: English. Geneva: OMC.

OMC. 2007C. WT/DS285/22. UNITED STATES - MEASURES AFFECTING THE CROSSBORDER SUPPLY OF GAMBLING AND BETTING SERVICES: Recourse by Antigua and Barbuda to Article 22.2 of the DSU. 22 June 2007. Original: English. Geneva: OMC.

OMC. 2007D. WT/DS285/ARB. UNITED STATES - MEASURES AFFECTING THE CROSSBORDER SUPPLY OF GAMBLING AND BETTING SERVICES: Recourse to Arbitration by the United States under Article 22.6 of the DSU - Decision by the Arbitrator. 21 December 2007. Original: English. Geneva: OMC.

OMC. 2008. WT/DS267/AB/RW. APPELLATE BODY REPORT - UNITED STATES - SUBSIDIES ON UPLAND COTTON - RECOURSE TO ARTICLE 21.5 OF THE DSU BY BRAZIL: - Report of the Appellate Body. 2 June 2008. Original: English. Geneva: OMC, 2008.

PAUWELYN, Joost. 2000. Enforcement and Countermeasures in the WTO: rules are rules - toward a more collective approach. American Journal of International Law, v. 94, n. 2, p. 335-347. 
RUSE-KHAN, Henning G. 2008. Suspending IP obligations under TRIPS: a viable alternative to enforce prevailing WTO rulings? Geneva (CHE): Center for International Environmental Law. Disponível em: $<$ http://www.ciel.org/Publications/TRIPS_IP_7May08.pdf $>$. Acesso em: 20 jun. 2008.

SMITH, James M. 2003. Compliance Bargaining in the WTO: Ecuador and the Bananas Dispute. Trabalho apresentado à Conference on Developing Countries and the Trade Negotiation Process UNCTAD (November 2003). Disponível em: <http://www.ruig-gian.org/ressources/dupont-Smith. pdf>. Acesso em: 10 dez. 2007.

SPADANO, Lucas E.F.A.. 2005. Cross-agreement retaliation in the WTO dispute settlement system: an important enforcement mechanism for developing countries? Trabalho apresentado à London School of Economics and Political Science, Law Department (September, 2005).

SUBRAMANIAN, Arvind; WATAL Jayashree. Can TRIPS Serve as an Enforcement Device for Developing Countries in the WTO? Journal of International Economic Law, v. 3, n. 3, p. 403-416, 2000 .

SUTHERLAND, Peter et al. The future of the WTO: addressing institutional challenges in the new millennium. Geneva (CHE): WTO Publications, 2004.

UNCTAD-ICTSD. 2006. Exceptions to Patent Rights in Developing Countries. Issue Paper n. 17. Geneva (CHE): UNCTAD. Disponível em <http://www.unctad.org/en/docs/iteipc200612_en.pdf> Acesso em: 01 mar. 2008.

VALOR ECONÔMICO. 2008. País vence disputa por algodão e pode retaliar EUA. Sergio Leo. 3 Junho 2008. Disponível em <http://www.valoronline.com.br/valoreconomico/285/primeirocaderno /brasil/Pais+vence+disputa+por++algodao+e+pode+retaliar+EUA,,63,4960945.html $>$. Acesso em: 03 jun. 2008. 